\title{
Efecto sobre la fermentación in vitro de mezclas de Tithonia diversifolia, Cenchrus clandestinum y grasas poliinsaturadas ${ }^{1}$
}

\author{
Effect on of in vitro fermentation of mixture of Tithonia diversifolia, \\ Cenchrus clandestinum and polyunsaturated fats
}

\author{
Juan Leonardo Cardona-Iglesias², Liliana Mahecha-Ledesma², Joaquín Angulo-Arizala ${ }^{2}$
}

\begin{abstract}
Resumen
El objetivo del presente trabajo fue evaluar mediante estudios in vitro, el efecto de la mezcla de botón de oro (Tithonia diversifolia), kikuyo (Cenchrus clandestinum) y alimento concentrado, con la adición de diferentes niveles de ácidos grasos polinsaturados (AGPI), sobre la producción de metano $\left(\mathrm{CH}_{4} \mathrm{ml} / \mathrm{g} \mathrm{MSd}\right)$, digestibilidad de la materia seca (\%DIVMS) y producción de ácidos grasos volátiles (AGV). La investigación se llevó a cabo en el laboratorio NUTRILAB (Medellín, Colombia) en septiembre del año 2015. Se utilizaron tres combinaciones de fuentes lipídicas ricas en AGPI con un nivel total máximo de inclusión correspondiente al 3\% de la materia seca incubada. Las combinaciones de fuentes lipídicas fueron: SAGPI1: $0,5 \%$-aceite soya, $0,5 \%$-aceite pescado, $2 \%$ grasa sobrepasante rica en omega 3. SAGPI2: $1 \%$ aceite soya, $0,5 \%$ aceite pescado, $1,5 \%$-grasa sobrepasante rica en omega 3 . SAGPI3: $2,5 \%$ aceite soya, $0,5 \%$ aceite pescado. También se utilizó una fuente de grasa sobrepasante (GSP). Los resultados obtenidos fueron procesados con base en la prueba de comparaciones preplaneadas a través del PROC-MIXED de SAS. La producción de metano in vitro disminuyó $(\mathrm{p}<0,05)$, mientras que la digestibilidad de la materia seca incrementó $(\mathrm{p}<0,05)$ a las 24 y 48 horas al incluir botón de oro y/o AGPI o ambos en las mezclas. En la proporción molar de AGV (\%), el ácido acético fue el que mayor presencia evidenció. La inclusión de forrajeras como el botón de oro y la suplementación con fuentes de AGPI en bovinos, podría ser una estrategia para reducir emisiones de metano sin detrimento de la fermentación ruminal.
\end{abstract}

Palabras claves: ácidos grasos poliinsaturados, metanogénesis, sistema silvopastoril, digestibilidad in vitro.

\begin{abstract}
The aim of this study was evaluated by in vitro, the effect of mixing wild sunflower (Tithonia diversifolia), kikuyu (Cenchrus clandestinum) and concentrated feed, with the addition of polyunsaturated fatty acids (AGPI) on the production of methane $\left(\mathrm{CH}_{4} \mathrm{ml} / \mathrm{g}\right.$ MSd), dry matter digestibility (\%DIVMS) and production of volatile fatty acids (AGV). The research was conducted in NUTRILAB laboratory (Medellin, Colombia) in September 2015. Three
\end{abstract}

\footnotetext{
Recibido: 19 de julio, 2016. Aceptado: 28 de setiembre, 2016. Este trabajo formó parte de la tesis de grado de la maestría en Ciencias Animales del primer autor, en la Facultad de Ciencias Agrarias de la Universidad de Antioquia. Financiado por el proyecto "Fortalecimiento de la producción de la cadena láctea del distrito Norte Antioqueño", convenio No 2012AS180031 firmado entre la Secretaría de Agricultura y Desarrollo Rural del Departamento de Antioquia, la Universidad Nacional de Colombia (sede Medellín) y la Universidad de Antioquia, con recursos del Sistema General de Regalías (SGR). Colombia.

2 Universidad de Antioquia, Facultad de Ciencias Agrarias, Grupo de Investigación en Ciencias Agrarias (GRICA). AA 1126, Medellín, Colombia.jleonardo.cardona@udea.edu.co, liliana.mahecha@udea.edu.co (autora para correspondencia), joaquin.angulo@udea.edu.co
} 
combinations of AGPI rich lipid sources were used with a total maximum inclusion level corresponding to $3 \%$ of incubated dry matter. Combinations of lipid sources were: SAGPI1: $0.5 \%$ soya oil, $0.5 \%$ fish oil, $2 \%$ rich in omega 3 bypass fat. SAGPI2: $1 \%$ Soya oil, $0.5 \%$ fish oil, $1.5 \%$ bypass fat rich in omega 3. SAGPI3: 2.5\% Soya oil, $0.5 \%$ fish oil. A source of bypass fat (GSP) was also used. The results were processed using pre-planned test comparisons through the PROC MIXED-SAS.The methane production in vitro decreased $(\mathrm{p}<0.05)$, while the dry matter digestibility increased $(\mathrm{p}<0.05) 24$ and 48 hours after wild sunflower was include and / or AGPI or both into the mixtures. In the molar ratio of AGV (\%), acetic acid showed an increased presence. The inclusion of forage like wild sunflower and sources of AGPI supplementation in cattle, could be a strategy to reduce methane emissions without causing a detriment to the ruminal fermentation.

Keywords: polyunsaturated fatty acids, methanogenesis, silvopastoral system, in vitro digestibility.

\section{Introducción}

El cambio climático es una realidad, el planeta Tierra está sufriendo un aumento del efecto invernadero, causado, entre otros, por el incremento de la concentración de diferentes gases que se acumulan y retienen el calor en la atmósfera (Carmona et al., 2005; Soliva y Hess, 2007). La acumulación de los gases de efecto invernadero (GEI) está conllevando a cambios repentinos en los patrones climáticos a nivel global (IPCC, 2007). El metano $\left(\mathrm{CH}_{4}\right)$ es el GEI que más ha aumentado sus concentraciones atmosféricas en el último siglo, una proporción de este gas proviene de la actividad ganadera, sobre todo de la fermentación entérica de los alimentos en los rumiantes (FAO, 2009; Marín, 2013). Durante la fermentación anaeróbica de los carbohidratos de la dieta, se produce el $\mathrm{CH}_{4}$ por parte de microorganismos ruminales procariotas del subgrupo Archea, los cuales viven en medios estrictamente anaerobios y obtienen la energía para su proliferación mediante la síntesis de este gas (Kurihara et al., 1999; Deppenmeier y Müller, 2008). La producción de $\mathrm{CH}_{4}$ es importante, ya que es una forma de disminuir la concentración de hidrógeno $\left(\mathrm{H}_{2}\right)$ en el rumen y así mantener estable su funcionamiento (Schink, 2006).

Existen otras vías de remoción del $\mathrm{H}_{2}$ ruminal, como lo es por ejemplo, el proceso de biohidrogenación de los ácidos grasos insaturados o la formación de ácido propiónico (Van Soest, 1994). La disminución parcial de la concentración de $\mathrm{H}_{2}$ en rumen, es importante debido a que los microorganismos metanogénicos utilizan como sustrato el $\mathrm{H}_{2}$ en un $80 \%$ para sintetizar $\mathrm{CH}_{4}$ (Demeyer y Fievez, 2000). Desde el ámbito ambiental cabe anotar que el $\mathrm{CH}_{4}$ es un gas con la capacidad de almacenar calor en la atmósfera, veintiún veces más que el dióxido de carbono $\left(\mathrm{CO}_{2}\right)$. Por lo anterior, se ha relacionado a los rumiantes como contribuyentes de la emisión de gases de efecto invernadero (Arcuri et al., 2006). Desde el punto de vista de eficiencia productiva, las emisiones de $\mathrm{CH}_{4}$ provocan pérdidas energéticas en los rumiantes que pueden variar entre 5,5 y $13 \%$ de la energía bruta consumida por el animal (Wolin y Miller, 2006), lo cual afecta negativamente el desempeño productivo. Las dietas basadas en forrajes de baja calidad, tienden a mantener un pH básico y están asociadas a una alta producción de $\mathrm{CH}_{4}$ (Moss et al., 2000), mientras que dietas que garanticen contenidos medios a altos de carbohidratos solubles tienden a disminuirlo.

La producción de $\mathrm{CH}_{4}$ a nivel ruminal, también está relacionado con el nivel de consumo de materia seca (CMS), existiendo una correlación negativa entre la digestibilidad de las dietas y la producción de este gas (Cambra et al., 2008). La búsqueda de alternativas que permitan reducir la emisión de $\mathrm{CH}_{4}$ por parte de la ganadería en condiciones comerciales es un tema de gran importancia en la actualidad. El uso de algunas especies forrajeras tropicales en la alimentación de rumiantes, ha demostrado disminuir la síntesis de $\mathrm{CH}_{4}$, debido a la presencia de compuestos como los taninos y saponinas, los cuales al parecer tienen cierto efecto antimetanogénico, mostrando así una importante disminución en la producción de $\mathrm{CH}_{4}$ por unidad de forraje digerido (Navas, 2008; Angarita, 
2013). Una especie forrajera que se viene evaluando como recurso para la alimentación de rumiantes es la Tithonia diversifolia, debido, entre otros, a su buen valor nutricional (balance proteína-carbohidratos solubles) (Medina et al., 2009) y al control de microorganismos metanogénicos con la consecuente disminución de $\mathrm{CH}_{4}$ observado en pruebas in vitro (Galindo et al., 2011; Mauricio et al., 2014).

La adición de ciertas fuentes de lípidos en las dietas para rumiantes, especialmente aquellos poliinsaturados, podría llegar a constituir una alternativa dietaria, con el fin de tratar de disminuir la metanogénesis a nivel ruminal (Martin et al., 2010). Lo anterior, ha sido relacionado a que parece que los lípidos tienen un efecto tóxico sobre microorganismos metanogénicos de tipo Archea y protozoarios, además, los lípidos insaturados tienen la capacidad de captar ciertas cantidades de $\mathrm{H}_{2}$ durante el proceso de biohidrogenación ruminal (Jalc et al., 2002). La disminución de metano cuando se utiliza la adición de lípidos, depende principalmente de la concentración y la composición de los ácidos grasos de las dietas (Beauchemin et al., 2008). Además de dietas que procuren disminuir la producción de $\mathrm{CH}_{4}$ entérico, es necesario potencializar la digestibilidad ruminal de los componentes de la dieta, ya que las estrategias con fines antimetanogénicas deben ir acompañadas de aspectos que a la vez, mejoren el desempeño animal.

Las técnicas in vitro son metodologías rápidas y de gran reproducibilidad, que no provocan invasión en los animales y permiten evaluar aspectos de la cinética y fermentación ruminal, para comparar así las diferencias nutritivas entre diferentes materias primas o dietas destinadas para la alimentación animal (La O et al., 2012).

El objetivo del presente trabajo fue evaluar mediante estudios in vitro, el efecto de la mezcla de botón de oro (Tithonia diversifolia), kikuyo (Cenchrus clandestinum) y alimento concentrado, con la adición de diferentes niveles de ácidos grasos poliinsaturados, sobre la producción de metano, la digestibilidad de la materia seca y la producción de ácidos grasos volátiles.

\section{Materiales y métodos}

\section{Localización}

El experimento se desarrolló durante el segundo semestre del 2015 en el Laboratorio de Investigación y Nutrición Animal (NUTRILAB), ubicado en la Sede de Investigación Universitaria (SIU) de la Universidad de Antioquia,

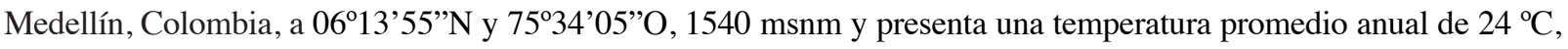
humedad relativa del $68 \%$ y precipitación media anual de 1600 mm (IDEAM, 1999).

\section{Sustratos experimentales}

Se evaluaron once sustratos que estuvieron conformados por forrajes solos, la combinación entre ellos con concentrado y la adición o no de tres combinaciones de fuentes de ácidos grasos poliinsaturados (AGPI). A los testigos que no incluyeron AGPI, se les adicionó una grasa comercial saturada protegida (GSP) de la acción de los microorganismos del inóculo ruminal, con el fin de garantizar que los sustratos que incluyeron la adición de AGPI fueran isoenergéticos respecto a ellos (Cuadro 1). Los forrajes utilizados fueron botón de oro (BO) (Tithonia diversifolia Hemsl. A Gray) de setenta días de edad y kikuyo (Cenchrus clandestinus Hochst. ex Chiov) de 35 días de edad, provenientes de un sistema silvopastoril (SSP) de trópico de altura (2400 msnm-temperatura promedio $15^{\circ}$ C). Se empleó un alimento concentrado comercial para vacas holstein.

La composición química del forraje y el alimento concentrado utilizado se presenta en el Cuadro 2 y se desarrolló mediante técnicas analíticas convencionales de la AOAC (1999). La cuantificación de los taninos condensados totales (unidad de medida: catequina) para las muestras de BO y el suplemento concentrado, se realizó 
Cuadro 1. Descripción de los sustratos (base seca) evaluados in vitro, para la medición de la producción de metano, la digestibilidad de la materia seca, y la producción de ácidos grasos volátiles, en vacas holstein. Medellín, Colombia. 2016.

Table 1. Description of substrates (dry basis) evaluated in vitro, for measuring methane production, the dry matter digestibility, and volatile fatty acids production in Holstein cows. Medellin, Colombia. 2016.

\begin{tabular}{|c|c|c|c|c|c|c|c|}
\hline \multirow[t]{2}{*}{ Sustratos } & \multicolumn{7}{|c|}{$\%$ de inclusión } \\
\hline & BO & $\mathbf{K}$ & $\mathbf{C}$ & GSP & SAGPI 1 & SAGPI 2 & SAGPI 3 \\
\hline $\mathrm{BO}$ & 100 & & & & & & \\
\hline $\mathrm{BO}+\mathrm{K}$ & 5 & 95 & & & & & \\
\hline $\mathrm{BO}+\mathrm{K}+\mathrm{C}+\mathrm{GSP}(\mathrm{SSP})$ testigo & 3 & 57 & 37 & 3 & & & \\
\hline $\mathrm{BO}+\mathrm{K}+\mathrm{C}+\mathrm{SAGPI} 1$ & 3 & 57 & 37 & & 0,5 & 0,5 & 2 \\
\hline $\mathrm{BO}+\mathrm{K}+\mathrm{C}+\mathrm{SAGPI} 2$ & 3 & 57 & 37 & & 1 & 0,5 & 1,5 \\
\hline $\mathrm{BO}+\mathrm{K}+\mathrm{C}+\mathrm{SAGPI} 3$ & 3 & 57 & 37 & & 2,5 & 0,5 & 0 \\
\hline $\mathrm{K}$ & & 100 & & & & & \\
\hline \multicolumn{8}{|l|}{$\mathrm{K}+\mathrm{C}+\mathrm{GSP}(\mathrm{MONO})$} \\
\hline Testigo & & 60 & 37 & 3 & & & \\
\hline $\mathrm{K}+\mathrm{C}+\mathrm{SAGPI} 1$ & & 60 & 37 & & 0,5 & 0,5 & 2 \\
\hline $\mathrm{K}+\mathrm{C}+\mathrm{SAGPI} 2$ & & 60 & 37 & & 1 & 0,5 & 1,5 \\
\hline $\mathrm{K}+\mathrm{C}+\mathrm{SAGPI} 3$ & & 60 & 37 & & 2,5 & 0,5 & 0 \\
\hline
\end{tabular}

BO: botón de oro, K: kikuyo, C: alimento concentrado, GSP: grasa sobrepasante saturada, SAGPI: suplementación de ácidos grasos polinsaturados, SAGPI1: $0,5 \%$ de aceite soya, $0,5 \%$ aceite de pescado y $2 \%$ de $n 3$ sobrepasante, SAGPI2: $1 \%$ de aceite de soya, $0,5 \%$ aceite de pescado y $1,5 \%$ de n3 sobrepasante, SAGPI3: 2,5\% de aceite de soya, $0,5 \%$ aceite de de pescado / BO: wild sunflower, K: kikuyu, C: concentrate food, GSP: saturated bypass fat, SAGPI: polyunsaturated fatty acid supplementation, SAGPI1: $0.5 \%$ of soya oil, $0.5 \%$ of fish oil and $2 \%$ of the overtaking n3, SAGPI2: $1 \%$ of soya oil, $0,5 \%$, of fish oil and $1,5 \%$ of the overtaking n3, SAGPI3: $2.5 \%$ of soya oil, $0.5 \%$ of fish oil.

Cuadro 2. Composición química de los sustratos, empleados para medir la producción de metano, la digestibilidad de la materia seca, y la producción de ácidos grasos volátiles, expresada como porcentaje de la materia seca (MS), en vacas holstein. Medellín, Colombia. 2016.

Table 2. Chemical composition of the substrates, used for measuring methane production, the dry matter digestibility, and production of volatile fatty acids, expressed as a percentage of dry matter (MS), in Holstein cows. Medellin, Colombia. 2016.

\begin{tabular}{lccc}
\hline Composición química* & Tithonia diversifolia & P. clandestinum & Concentrado \\
\hline PC & 17,2 & 19,2 & 14 \\
FDN & 39 & 55 & 14,3 \\
FDA & 27,2 & 24 & 5,4 \\
Cen & 12,5 & 11,6 & 6,4 \\
Ca & 0,8 & 0,4 & 1,2 \\
P & 0,35 & 0,2 & 0,42 \\
E.E & 1,1 & 2,2 & 5,1 \\
E.L.N & 29,5 & 12 & 60,2 \\
\hline \multicolumn{4}{c}{0,5} \\
\hline \multicolumn{4}{c}{ Taninos concentrados (g catequina/kg MS) } \\
\hline
\end{tabular}

Taninos condensados como g catequina/kg MS y saponinas como g diosgenina/kg MS / Condensed tannins as catechin $\mathrm{g} / \mathrm{kg}$ MS and saponins such as diosgenin $\mathrm{g} / \mathrm{kg}$ MS.

*PC: proteína cruda, FDN: fibra detergente neutra, FDA: fibra detergente ácida, Cen: cenizas, Ca: calcio, P: fósforo, E.E: extracto etéreo, ELN: extracto libre de nitrógeno / PC: crude protein, NDF: neutral detergent fiber, FDA: acid detergent fiber, Cen: ash, Ca: calcium, P: phosphorus, EE: ether extract, ELN: nitrogen-free extract. 
mediante el método de Chavan et al. (2001), en el Laboratorio Ciencia de los Alimentos de la Universidad Nacional de Colombia sede Medellín, mientras que los análisis para saponinas (unidad de medida: diosgenina) se realizaron por la metodología descrita por Hiai et al. (1976), en el Laboratorio Nutrianálisis (Bogotá D.C, Colombia). Se consideró que la producción de metano puede variar de acuerdo con el nivel de los componentes del alimento concentrado, por lo que se utilizó el mismo tipo y proporción en las mezclas.

La relación forraje:concentrado y BO:kikuyo fue obtenida del promedio estimado en una fase inicial de caracterización de ambos sistemas (SSP y monocultivo). Este se llevó a cabo mediante una investigación en el primer semestre del año 2015, donde se evaluó la produción, calidad de forraje, relación BO:kikuyo y el consumo de materia seca (CMS) en ambos sistemas (datos sin publicar por el autor). Los forrajes fueron recolectados en un SSP para ramoneo de trópico de altura, en la finca La Montaña perteneciente a la Universidad de Antioquia, dicho predio se encuentra ubicado en el municipio de San Pedro de los Milagros (Antioquia, Colombia), en una zona de vida bosque húmedo montano bajo (bh-Mb). Del BO se cosechó la parte consumible por los bovinos, es decir, hojas y tallos tiernos, del pasto kikuyo también se recolectó lo consumible por el animal según inspección visual (La O et al., 2012; Puerto, 2012; Santacoloma y Granados, 2012; Ramírez et al., 2015a). Posteriormente, dichos forrajes fueron trasladados al Laboratorio de Nutrición Animal, Pastos y Forrajes de la Universidad de Antioquia, ubicado en Medellín, Colombia, donde se secaron en estufa de ventilación forzada a $65^{\circ} \mathrm{C}$ por $72 \mathrm{~h} \mathrm{luego,} \mathrm{tanto} \mathrm{los} \mathrm{forrajes} \mathrm{como}$ el alimento concentrado, fueron molidos a $1 \mathrm{~mm}$, con un molino estacionario Thomas-Wiley modelo 4. La preparación de los once sustratos experimentales y los análisis bromatológicos de los forrajes y el suplemento concentrado se realizaron en el laboratorio anteriormente citado.

\section{Producción de metano y perfil de la fermentación in vitro}

La incubación se llevó a cabo en frascos de vidrio oscuros con capacidad de $100 \mathrm{ml}$ cada uno. En cada frasco se adicionó $0,5 \mathrm{~g}$ de sustrato seco y molido a $1 \mathrm{~mm}$, de acuerdo con la participación porcentual de cada sustrato en los tratamientos experimentales. Tres inóculos ruminales se obtuvieron de vacas holstein friesian adultas, con peso vivo promedio de $650 \mathrm{~kg} \pm 25$, provistas de cánula ruminal permanente, solo destinadas para investigación y pertenecientes a la hacienda La Montaña. Los animales donadores del inóculo permanecieron en condiciones de pastoreo permanente, en praderas de pasto kikuyo con edad promedio entre 35 a 45 días, sal mineralizada y agua a voluntad en el potrero. Los inóculos se recolectaron en horas de la mañana (6:00 am) con los animales en ayuno, y se transportaron en termos precalentados con agua a $40{ }^{\circ} \mathrm{C}$ hasta el laboratorio NUTRILAB. En el laboratorio, los inóculos se filtraron a través de un paño de algodón, se gasearon con $\mathrm{CO}_{2}$ y conservaron en baño maría durante el proceso de inoculación.

La solución buffer (saliva artificial) se preparó de acuerdo con las recomendaciones de McDougall (1948), se utilizó una relación buffer/inóculo ruminal de $9 / 1(45 / 5 \mathrm{ml} / \mathrm{ml})$. Los frascos con la saliva artificial permanecieron en estufa de ventilación forzada a $39^{\circ} \mathrm{C}$ por $6 \mathrm{~h}$, antes de la inoculación con fluido ruminal. Los frascos de incubación con el sustrato y la solución buffer, al inocularse con el líquido ruminal se sellaron con tapas de caucho. Los frascos dentro de la estufa de ventilación forzada $\left(39^{\circ} \mathrm{C}\right)$ se dispusieron en cajas de icopor para ayudar a conservar la temperatura.

En total se inocularon 144 frascos, 132 contenían sustrato e inóculo (11 tratamientos * 3 repeticiones/ tratamiento (inóculos) * 2 horarios de lectura * 2 réplicas por horario) y 12 correspondientes a los blancos $(2$ horarios * 3 inóculos * 2 blancos por horario) contenían solución tampón e inóculo pero sin sustrato, cuya función fue corregir la producción de gas generada por los microrganismos ruminales.

La presión generada por los gases producto de la fermentación, medida en libras por pulgada cuadrada (PSI), fue cuantificada con un transductor digital a las 24 y $48 \mathrm{~h}$ de incubación, como lo descrito por Theodorou et al. 
(1994). Para transformar los datos de presión (PSI) $(x)$ en volumen de gas $(\mathrm{ml})(y)$, se utilizó la ecuación $\mathrm{Y}=$ $-0,1375+\left(5,1385 \mathrm{X}+0,0777 \mathrm{X}^{2}\right)$ obtenida por Posada et al. (2006), y la producción de gas fue expresada por gramo de materia seca degradada (MSd). La concentración de metano de los tratamientos experimentales se determinó en el gas acumulado entre los intervalos de lectura (0-24 y 0-48 h). La colecta de gas se realizó utilizando una válvula de tres salidas. La primera salida se conectó a una aguja $(0,6 \mathrm{~mm})$, la segunda al transductor de presión y la tercera a una jeringa plástica que sirvió para la extracción del volumen de gas.

La aguja acoplada a la válvula se insertó a través de la tapa de caucho para la medición de la presión y posteriormente, los gases acumulados en la parte superior del frasco se retiraron con el uso de la jeringa hasta el punto en que la presión registrada en el transductor alcanzó a ser cero. El gas colectado en la jeringa se trasladó y almacenó en bolsas plásticas herméticamente cerradas, a partir de las cuales se tomaron muestras de $100 \mu 1$, que se inyectaron en un cromatógrafo de gases adaptado con un detector de ionización de llama (FID). Las condiciones cromatográficas se adaptaron de Apráez et al. (2012). Los datos de concentración de metano se procesaron de acuerdo con la descripción dada por López y Newbold (2007), la producción de este (ml) se obtuvo del producto entre el volumen total de gas $(\mathrm{ml})$ y la concentración relativa de metano.

\section{Digestibilidad de la materia seca}

La digestibilidad de la materia seca (DMS), expresada en porcentaje (\%), se determinó a las 24 y $48 \mathrm{~h} . \mathrm{Al}$ finalizar la incubación, el contenido de los frascos se filtró con crisoles de peso conocido; se utilizó una bomba de vacío. El residuo resultante se secó en horno durante $48 \mathrm{~h}$ a $65{ }^{\circ} \mathrm{C}$, luego se pesó y se usó para calcular por gravimetría (diferencia entre el material incubado y el residuo después del secado) la digestibilidad de la MS (García-González et al., 2008). Después de obtener los valores de producción de gas y la materia seca digestible (MSD), se calculó el factor de partición (FP), correspondiente a los mg de materia seca digestible (MSD) por cada $\mathrm{ml}$ de gas producido (MSD/volumen gas, $\mathrm{mg} / \mathrm{ml}$ ).

\section{Determinación del perfil de la fermentación}

La concentración de ácidos grasos volátiles (AGV) (acético, propiónico y butírico) se determinó en el líquido resultante de la filtración de los crisoles a las 24 y 48 h de incubación. Este líquido se preservó mediante la adición de ácido sulfúrico (98\% v/v) hasta alcanzar un pH de 2 aproximadamente, y luego se centrifugó repetidas veces a $4000 \mathrm{rpm}$, hasta no observar presencia de precipitado (Ramírez et al., 2015a; Ramírez et al., 2015b). Antes de la acidificación, se determinó el pH con pH-metro digital. Para la determinación de AGV, muestras de $1 \mu \mathrm{l}$ de líquido se inyectaron en un cromatógrafo de gases Thermo Trace GC Ultra equipado con un detector FID y una columna de $30 \mathrm{~m}, 0,32 \mathrm{~mm}$ y $0,25 \mu \mathrm{m}$.

Las temperaturas del inyector y del detector fueron de 210 y $300^{\circ} \mathrm{C}$, respectivamente; para el horno, la temperatura inicial fue de $68{ }^{\circ} \mathrm{C}(1 \mathrm{~min})$, luego aumentó $10{ }^{\circ} \mathrm{C} / \mathrm{min}$ hasta alcanzar $140{ }^{\circ} \mathrm{C}(1 \mathrm{~min})$, y posteriormente $40{ }^{\circ} \mathrm{C} / \mathrm{min}$ hasta alcanzar $200{ }^{\circ} \mathrm{C}(1 \mathrm{~min})$. El modo de inyección fue split y como gas de arrastre se utilizó helio $(2,5 \mathrm{ml} / \mathrm{min})$. La concentración de AGV (mmol/l) se calculó a partir de la concentración (ppm) determinada por cromatografía y asumiendo una masa molar de 60,05,74,08 y 88,11 g/mol para el ácido acético, propiónico y butírico, respectivamente.

\section{Análisis estadístico de la información}

Los datos se analizaron empleando un diseño completamente aleatorizado con arreglo factorial (11 tratamientos x 2 horarios de evaluación ( 24 y 48 h)). Este modelo consideró como efectos fijos el tratamiento evaluado, el horario de medición y la interacción entre estos dos factores, y como efecto aleatorio el inóculo ruminal. Dada la 
magnitud (cantidad) de los tratamientos y, por considerar de interés el efecto que pudieran tener las mezclas de los sustratos que provenían de un sistema silvopastoril (con botón de oro) o en pastoreo tradicional (solo kikuyo) y con la adición de grasas poliinsaturadas, sobre las variables evaluadas, se realizó prueba de contrastes ortogonales, con el fin de aglomerar los tratamientos en grupos afines y así obtener mejor explicación de los resultados.

A priori se plantearon comparaciones planeadas, para hacer el análisis de contrastes, tal como se indica más adelante. Para las variables metano y DIVMS, por ser las variables de mayor interés en el análisis, además de las comparaciones, se presentó la interacción entre los once tratamientos (sustratos) para ambos horarios de evaluación. En el análisis de la información se empleó el procedimiento MIXED del paquete estadístico SAS (2004). Las diferencias entre promedios se analizaron mediante prueba de Tukey con un nivel de confianza del $5 \%$.

Las comparaciones pre-planeadas fueron:

- $\mathrm{BO}+\mathrm{K}+\mathrm{C}+\mathrm{GSP}$ vs $\mathrm{K}+\mathrm{C}+\mathrm{GSP}$. Con esta comparación se simularon dos dietas de animales, una en un SSP y la otra en un sistema tradicional de pastoreo en monocultivo de gramínea. En adelante esta comparación se llamará SSP vs MONO.

- $\quad \mathrm{BO}+\mathrm{K}+\mathrm{C}+\mathrm{GSP}$ vs $(\mathrm{BO}+\mathrm{K}+\mathrm{C}+\mathrm{SAGPI} 1)+(\mathrm{BO}+\mathrm{K}+\mathrm{C}+\mathrm{SAGPI})+(\mathrm{BO}+\mathrm{K}+\mathrm{C}+\mathrm{SAGPI})$. Con esta comparación se simularon las dietas que tendrían los animales en un SSP y en SSP con adición de grasas poliinsaturadas. En adelante esta comparación se llamará SSP vs SSP+ $\sum \mathrm{SAGPI}$.

- $\quad \mathrm{K}+\mathrm{C}+\mathrm{GSP}$ vs $(\mathrm{K}+\mathrm{C}+\mathrm{SAGPI} 1)+(\mathrm{K}+\mathrm{C}+\mathrm{SAGPI} 2)+(\mathrm{K}+\mathrm{C}+\mathrm{SAGPI} 3)$. Con esta comparación se simularon las dietas que tendrían en un sistema tradicional de pastoreo en monocultivo de gramínea y la que tendrían en este mismo sistema con la adición de grasas poliinsaturadas. En adelante esta comparación se llamará MONO vs $\mathrm{MONO}+\sum \mathrm{SAGPI}$.

- $\quad(\mathrm{BO}+\mathrm{K}+\mathrm{C}+\mathrm{SAGPI} 1)+(\mathrm{BO}+\mathrm{K}+\mathrm{C}+\mathrm{SAGPI} 2)+(\mathrm{BO}+\mathrm{K}+\mathrm{C}+\mathrm{SAGPI})$ vs $(\mathrm{K}+\mathrm{C}+\mathrm{SAGPI} 1)+(\mathrm{K}+\mathrm{C}+\mathrm{SAGPI} 2)$ $+(\mathrm{K}+\mathrm{C}+\mathrm{SAGPI})$. Esta comparación simuló las dietas que tendrían los animales en un SSP con la adición de grasas poliinsaturadas y la que tendrían en un sistema tradicional de pastoreo en monocultivo de gramínea con la adición de grasas poliinsaturadas. En adelante esta comparación se llamará SSP $+\sum$ SAGPI vs MONO $+\sum$ SAGPI.

- $\quad \mathrm{K}+\mathrm{C}+\mathrm{GSP}$ vs $(\mathrm{BO}+\mathrm{K}+\mathrm{C}+\mathrm{SAGPI} 1)+(\mathrm{BO}+\mathrm{K}+\mathrm{C}+\mathrm{SAGPI})+(\mathrm{BO}+\mathrm{K}+\mathrm{C}+\mathrm{SAGPI})$. Con esta comparación se evaluó el efecto de la inclusión de BO y SAGPI. Se simuló la dieta que tendrían los animales en un sistema tradicional de pastoreo en monocultivo de gramínea y se comparó la que tendrían los animales en un sistema silvopastoril (que incluye BO) con la adición de grasas poliinsaturadas. En adelante esta comparación se llamará MONO vs SSP+ $\sum$ SAGPI.

- Sustratos con BO vs sustratos sin BO. Con esta comparación se contrastaron todos los sustratos que incluyeron $\mathrm{BO}$ frente a los sustratos que no incluyeron $\mathrm{BO}$, con el fin de evaluar el efecto del forraje en los sustratos evaluados. En adelante esta comparación se llamará Sust con BO vs Sust sin BO.

\section{Resultados y discusión}

\section{Producción de metano, degradabilidad y AGV}

\section{Producción de metano}

Hubo diferencia estadística significativa entre sustratos para la producción de metano en mililitros por gramo de materia seca degradada ( $\mathrm{Pdn} \mathrm{CH}_{4} \mathrm{ml} / \mathrm{g} \mathrm{MSd}$ ) en los intervalos 0-24 y 0-48 horas ( $\mathrm{p}<0,05$ ) (Cuadro 3). Asimismo, las comparaciones pre-planeadas realizadas mostraron diferencias estadísticas significativas $(\mathrm{p}<0,05)$ (Cuadro 4). 
Cuadro 3. Interacción entre los once sustratos empleados para medir la tasa de producción de metano (ml/g MSd) in vitro, en dos intervalos de tiempo, en vacas holstein. Medellín, Colombia. 2016.

Table 3. Interaction between the eleven substrates used to measure methane production rate ( $\mathrm{ml} / \mathrm{g}$ MSd) in vitro, in two time intervals, in Holstein cows. Medellin, Colombia. 2016.

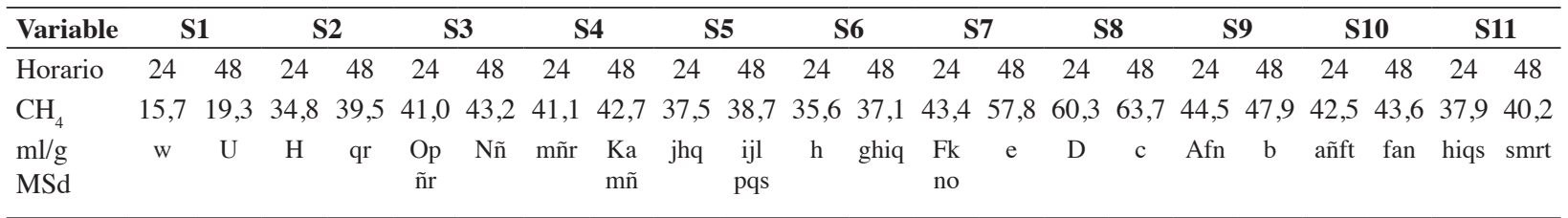

$\mathrm{S} 1$ : BO; $\mathrm{S} 2$ : BO+K; $\mathrm{S} 3$ : BO+K+C+GSP (SSP) testigo; S4: BO+K+C+SAGPI1; S5: BO+K+C+SAGPI2; S6: BO+K+C+SAGPI3; S7: K. S8: K+C+GSP (MONO) testigo; S9: K+C+SAGPI1; S10: K+C+SAGPI2; S11: K+C+SAGPI3; MSd: materia seca degradada; S: sustrato. Medias con diferente letra en la fila presentan diferencia estadística significativa $(\mathrm{p}<0,05)$ / Means with different letter in a row show a statistically significant difference $(\mathrm{p}<0.05)$.

S1: BO; S2: BO + K; S3: BO + K + C + GSP (SSP) control; S4: BO + K + C + SAGPI1; S5: BO + K + C + SAGPI2; S6: BO + K + C + SAGPI3; S7: K; S8: K + C + GSP (MONO) control; S9: K + C + SAGPI1; S10: K + C + SAGPI2; S11: K + C + SAGPI3; MSd: degraded dry matter; S: substrate.

Cuadro 4. Comparaciones utilizadas para contrastar la tasa de producción de metano (ml/g MSd) in vitro, entre distintos grupos de sustratos con la inclusión de botón de oro (BO) y/o fuentes de ácidos grasos poliinsaturados (AGPI), en dos intervalos de tiempo, en vacas holstein. Medellín, Colombia. 2016

Table 4. Comparisons used to test the methane production rate ( $\mathrm{ml} / \mathrm{g} \mathrm{MSd}$ ) in vitro, between different groups of substrates including wild sunflower (BO) and/or sources of polyunsatured fatty acids (AGPI), in two time intervals, in Holstein cows. Medellin, Colombia. 2016.

\begin{tabular}{|c|c|c|c|c|c|c|c|c|c|c|c|}
\hline \multirow[b]{2}{*}{ Variable } & \multirow[b]{2}{*}{$\begin{array}{c}\text { Intervalo } \\
\text { horas }\end{array}$} & \multicolumn{2}{|c|}{$\begin{array}{c}\text { SSP vs SSP + } \\
\Sigma \text { SAGPI }\end{array}$} & \multicolumn{2}{|c|}{$\begin{array}{c}\text { MONO vs } \\
\text { MONO+ }+\sum \text { SAGPI }\end{array}$} & \multicolumn{2}{|c|}{$\begin{array}{l}\text { SSP }+\sum \text { SAGPI vs } \\
\text { MONO+ }+\sum \text { SAGPI }\end{array}$} & \multicolumn{2}{|c|}{$\begin{array}{c}\text { MONO vs } \\
\text { SSP+ }+\sum \text { SAGPI }\end{array}$} & \multicolumn{2}{|c|}{$\begin{array}{l}\text { Sust con BO vs } \\
\text { Sust sin BO }\end{array}$} \\
\hline & & SSP & $\begin{array}{c}\text { SSP + } \\
\sum \text { AGPI }\end{array}$ & MONO & $\begin{array}{c}\text { MONO + } \\
\sum A G P I\end{array}$ & $\begin{array}{c}\text { SSP + } \\
\sum \text { AGPI }\end{array}$ & MONO+ $+\sum A G P I$ & MONO & $\begin{array}{c}\text { SSP + } \\
\sum \text { AGPI }\end{array}$ & $\begin{array}{l}\text { Ttos con } \\
\text { BO }\end{array}$ & $\begin{array}{l}\text { Ttos sin } \\
\text { B.O }\end{array}$ \\
\hline \multirow{2}{*}{$\begin{array}{l}\mathrm{CH}_{4} \mathrm{ml} \\
/ \mathrm{g} \mathrm{MSd}\end{array}$} & 24 & $41,1 \mathrm{a}$ & $38 b$ & $60,4 a$ & $41,7 b$ & $38 b$ & $41,7 \mathrm{a}$ & $60,4 a$ & $38 \mathrm{~b}$ & $34,5 b$ & $45,9 a$ \\
\hline & 48 & $43,3 \mathrm{a}$ & $39,5 b$ & $63,8 \mathrm{a}$ & $44 \mathrm{~b}$ & $39,5 b$ & $44^{\mathrm{a}}$ & $63,8 \mathrm{a}$ & $39,5 b$ & $36,8 b$ & $50,7 \mathrm{a}$ \\
\hline
\end{tabular}

SSP:BO+K+C+GSP (testigo); MONO:K+C+GSP (testigo); SSP+ $\mathrm{SAGPI}: \mathrm{B} . \mathrm{O}+\mathrm{K}+\mathrm{C}+(\mathrm{SAGPI} 1,2,3) ; \mathrm{MONO}+\sum \mathrm{SAGPI}$ : $\mathrm{K}+\mathrm{C}+(\mathrm{SAGPI} 1,2,3)$; MSd: materia seca degradada; Sust: sustrato / SSP: BO + K + C + GSP (control); MONO: GSP + K + C (control); SSP + $\Sigma$ SAGPI: B.O + K + C + (SAGPI 1, 2,3); $\Sigma$ SAGPI MONO: K + C + (SAGPI 1,2,3); MSd: degraded dry matter; Sust: substrate Medias con diferente letra en la fila presentan diferencia estadística significativa $(p<0,05)$ / Means with different letter in a row show a statistically significant difference $(\mathrm{p}<0.05)$.

\section{Efecto horario e interacción sustrato x horario}

Se encontró diferencia estadística significativa $(\mathrm{p}<0,05)$ en la producción de metano entre horarios, con mayor producción promedio de metano a las $48 \mathrm{~h}$. Sin embargo, hubo una interacción sustrato x horario significativa $(\mathrm{p}<0,05)$, lo que indica que no todos los sustratos tuvieron el mismo comportamiento a las 24 y $48 \mathrm{~h}$. Esto es coherente, debido a que es de esperarse que la producción de metano aumente con las horas de incubación, y que todos los sustratos se comporten de manera diferente a través del tiempo, debido a la naturaleza y composición química del sustrato (Cuadro 3). 


\section{Efecto sustrato}

El BO (T1) tuvo una menor producción de metano respecto al kikuyo (T7) $(\mathrm{p}<0,05)$ (Cuadro 3). Igualmente, al hacer la comparación de todos los sustratos que incluyeron $\mathrm{BO}$, se encontró una menor producción de metano en comparación de aquellos sustratos que no incluyeron la forrajera $(\mathrm{p}<0,05)$ (Cuadro 4). La comparación preplaneada que incluyó todos los sustratos con BO vs los sustratos sin BO produjeron 24,8\% y 27,4\% menos metano $\left(\mathrm{CH}_{4} \mathrm{ml} / \mathrm{g} \mathrm{MSd}\right)$ a las 24 y 48 h de incubación, respectivamente. Asimismo, al comparar S3 (sustrato que representó la dieta en un SSP conformada por BO, kikuyo, alimento concentrado y grasa saturada protegida) vs S8 (sustrato que representó la dieta en un monocultivo de pasto conformada por kikuyo, alimento concentrado y grasa saturada protegida), cuya única diferencia fue la presencia o no de $\mathrm{BO}$, se encontró que al incluir $\mathrm{BO}$ se produjo una reducción de metano de $31,4 \%$ y $32,1 \%$ a las 24 y 48 h de incubación, respectivamente $(\mathrm{p}<0,05)$.

La disminución en la producción de metano in vitro al incluir forrajeras como el $\mathrm{BO}$ en dietas para rumiantes, se ha relacionado con un mejor balance de nutrientes en la dieta y la presencia de metabolitos secundarios como los taninos o saponinas (Carmona et al., 2005; Galindo et al., 2012). A los taninos y a las saponinas se les atribuye un efecto directo sobre los metanógenos y los protozoos, relacionados con la formación de complejos con la pared celular, lo cual provoca cambios morfológicos (Smith et al., 2005; Zhou et al., 2011) e induce deficiencias nutricionales, lisis y muerte de las células (Posada et al., 2005). Teniendo en cuenta que alrededor del 25\% de los metanógenos ruminales vive en asociación con protozoos se espera que una reducción en los últimos disminuya los primeros (Newbold et al., 1997). El efecto sobre la producción de $\mathrm{CH}_{4}$ es muy variable y depende del tipo de metabolitos secundarios y su concentración en la planta. En el presente trabajo se evidenció presencia de metabolitos secundarios (taninos y saponinas), obteniéndose valores de taninos concentrados (TC) (se cuantificó catequina (polifenol) como unidad de medida) para el BO de 1,4 g/kg MS y para el alimento concentrado de 0,5 $\mathrm{g} / \mathrm{kg}$ MS. Verdecia et al. (2011) reportaron valores de $12,3 \mathrm{~g} / \mathrm{kg}$ de MS de taninos TC totales en plantas de BO de sesenta días de edad, mediante el método descrito por Porter et al. (1986).

El nivel de taninos extractables totales en forraje de BO puede estar entre 29,2 y 37,7 g/kg de MS, para hojas maduras y jóvenes, respectivamente (Makkar, 2003; Maina et al., 2012). Se debe tener en cuenta que la edad de la planta, parte de la planta, época o método de cuantificación, influyen en el valor del contenido de metabolitos secundarios. En cuanto a los valores de saponinas, se encontró para el BO 4,53 g/kg MS y para el alimento concentrado 1,02 g/kg MS. Con métodos cualitativos se ha encontrado presencia moderada de saponinas en follaje de BO (Santacoloma y Granados, 2012; Galindo et al., 2014). Los forrajes o suplementos que contienen metabolitos secundarios han sido asociados con la disminución de metano en pruebas in vitro (Patra y Saxena, 2010). En el presente estudio hubo presencia de taninos condensados y saponinas en el BO y el suplemento concentrado, lo que posiblemente contribuyó a la disminución de la cantidad de metano. Vargas et al. (2012) sugieren que la producción de $\mathrm{CH}_{4}$ en sistemas silvopastoriles puede ser mitigada a través de la presencia de taninos condensados, al incluir leguminosas o forrajeras en la dieta.

El efecto de los taninos sobre los metanógenos y protozoarios es variable y depende del tipo de taninos, su origen y los niveles de suplementación (Patra y Saxena, 2010; Galindo et al., 2014). Al mezclar BO con una gramínea tropical (Brachiaria brizantha cv. Marandu) en condiciones in vitro, en proporciones de 0, 25, 50, 75 y $100 \%$, se encontró una disminución significativa de metano cuando la proporción de BO en la mezcla fue igual o mayor al 50\% (Mauricio et al., 2014). Lo anterior se relaciona con lo reportado por Galindo et al. (2011), quienes encontraron una disminución en la población de microorganismos metanógenos y protozoos en rumen al incluir 10 y $20 \%$ de forraje de BO en base seca. A su vez, en un estudio in vitro sobre cuantificación de bacterias metanógenas totales, donde se incluyó BO en una dieta para rumiantes basada en pasto Estrella (Cynodon nlemfluencis), al incluir hasta el $70 \%$ de $\mathrm{BO}$ en la mezcla se encontraron valores de $1,24 \times 10^{10} \mathrm{UFC} / \mathrm{ml}$ (unidades formadoras de colonia) respecto a valores de $1,85 \times 10^{10} \mathrm{UFC} / \mathrm{ml}$ en el pasto solo (Delgado et al., 2012). 
Se han observado inclusiones hasta del 35\% de BO en el consumo voluntario de bovinos en pastoreo (Mahecha et al., 2007). En el presente trabajo, con una inclusión de BO de solo el 3\% de la MS, se logró una disminución en la producción de metano, lo que muestra un posible potencial de esta especie para la mitigación de la emisión de metano en bovinos pastoreando en sistemas silvopastoriles de trópico de altura. El efecto de la utilización de SAGPI en mezclas denominadas MONO, se evidenció al comparar la mezcla de SAGPI, kikuyo y alimento concentrado (S9, S10, S11) con una mezcla que no incluyó SAGPI (kikuyo, alimento concentrado y grasa saturada protegida, S8, mezcla denominada MONO).

Se encontró una reducción significativa de metano en ambos horarios. SAGP3 (2,5\% de aceite soya, 0,5\% aceite de pescado), kikuyo y suplemento concentrado (S11) tuvo la menor producción de metano en ambos horarios $(\mathrm{p}<0,05)$, seguida por la mezcla de SAGP2 ( $1 \%$ de aceite soya, $0,5 \%$ aceite de pescado y $1,5 \%$ de $\mathrm{n} 3$ sobrepasante), kikuyo y alimento concentrado de S10, y por la mezcla de SAGP1 (0,5\% de aceite soya, $0,5 \%$ aceite de pescado y $2 \%$ de $n 3$ sobrepasante), kikuyo y suplemento concentrado (S9), respectivamente (Cuadro 3).

S11 vs S8 redujo la producción de metano significativamente $(\mathrm{p}<0,05)$ en un $37,14 \%$ y $36,9 \%$ a las 24 y 48 h, respectivamente; también S10 vs S8 redujo significativamente en un 29,51\% y 31,50\% a las 24 y 48 h, respectivamente, la producción de este gas; al igual que S9 vs S8 lo redujo significativamente en un $26,2 \%$ y $24,8 \%$ a las 24 y 48 h, respectivamente. Estas diferencias fueron corroboradas cuando se realizó la comparación pre-planeada del MONO vs MONO+ $\sum$ SAGPI (Cuadro 4), mostrando una disminución del $31 \%$ en la producción de metano del MONO+ $\sum$ SAGPI vs MONO en ambos horarios de medición. Los anteriores resultados sugieren una efectividad al adicionar cualquiera de las mezclas evaluadas de SAGPI en este tipo de sistemas (MONO), teniendo un mayor potencial de reducción SAGP3. Varios autores han reportado que los ácidos grasos, en especial los insaturados, tienen la capacidad de capturar hidrógeno, sobre todo mediante el proceso de biohidrogenación ruminal (Beauchemin et al., 2008), lo que podría ser una alternativa en el control de la metanogénesis ruminal (Cieslak et al., 2012; Patra, 2013).

Aunque varios autores consideran que la cantidad de $\mathrm{H}_{2}$ utilizada en el proceso de biohidrogenación ruminal es muy baja y no excede el 1 a $2 \%$, otros autores coinciden en que este valor puede variar dependiendo de la fuente de lípidos, y podría ser una alternativa metabólica para la captación de $\mathrm{H}_{2}$ (Ramírez et al., 2014). Además, se relaciona el potencial antimetanogénico de los lípidos con un efecto tóxico sobre los protozoos y metanógenos en rumen (Janssen, 2010). La reducción de $\mathrm{CH}_{4}$ inducida por la adición de fuentes lipídicas a la dieta en rumiantes puede alcanzar hasta un 50\% (Machmüller et al., 1998). Se han encontrado reducciones de 5,6\% de metano por cada unidad porcentual de lípidos adicionado a la ración en bovinos (Beauchemin et al., 2008). El uso de aceites vegetales, como el de soya, es frecuente en dietas para rumiantes, mientras que el uso de aceites ricos en n-3, tales como el aceite de pescado, es poco común. Los aceites de origen marino basados en ácido n-3-eicosapentanoico (EPA) y ácido n-3-docosahexanoico (DHA), poseen una alta concentración de ácidos grasos insaturados de cadena larga, los cuales han demostrado tener potencial para disminuir la metanogénesis ruminal (Fievez et al., 2003).

En un experimento in vitro, se encontró que la utilización de DHA disminuyó la producción de $\mathrm{CH}_{4}$ hasta en un $80 \%$ en dietas para vacas lecheras (Fievez et al., 2007). Cieslak et al. (2012) evaluaron la adición de $50 \mathrm{~g} / \mathrm{kg}$ de materia seca (MS) de aceite de uva (69\% ácido linoléico), y encontraron que la adición del aceite no afectó la fermentación y presentó una disminución de $21 \%$ de metano a las 24 h de fermentación. Panyakaew et al. (2013) en estudio in vitro evaluaron aceite de coco en dosis de 80 y $120 \mathrm{mg}$, con y sin adición de $20 \mathrm{mg}$ de una mezcla de aceite rica en ácidos grasos poliinsaturados (AGPI), y encontraron una reducción en la producción de metano de 12,7 y $14,5 \%$ para las dosis de 80 y $120 \mathrm{mg}$ sin adición de AGPI y en 31 y $28 \%$ para las mismas dosis pero con adición de AGPI. La producción de $\mathrm{CH}_{4}$ es proporcional al grado de insaturación de los ácidos grasos y a su nivel de inclusión (Giger-Reverdin et al., 2004); en el presente estudio, al parecer, la fuente y el nivel de SAGPI utilizado fue suficiente para mostrar una depresión en la producción de metano. 
El efecto de la utilización de SAGPI en mezclas denominadas SSP, se evidenció al comparar la mezcla de SAGPI, BO, kikuyo y alimento concentrado (S4, S5, S6) con una mezcla que no incluía SAGPI (BO, kikuyo, alimento concentrado y grasa saturada protegida, $\mathrm{S} 3$, mezcla denominada SSP). Se encontró diferencia significativa $(\mathrm{p}<0,05)$ en la reducción de metano, dependiendo del tipo de SAGPI utilizado. Así, la utilización de SAGP1 (S4) no mostró diferencia estadística en ninguno de los horarios evaluados, mientras que SAGP2 (S5) y SAGP3 (S6) sí mostraron diferencias estadísticas significativas $(\mathrm{p}<0,05)$ en ambos horarios, comparadas con S3 (Cuadro 3). S6 vs S3 redujo la producción de metano significativamente en un $13,2 \%(\mathrm{p}=0,0153)$ y $14,2 \%(\mathrm{p}=0,0121)$ a las 24 y $48 \mathrm{~h}$, respectivamente; S5 vs S3 también la redujo significativamente en un $8,53 \%(\mathrm{p}=0,0165)$ y $10,40 \%(\mathrm{p}=0,0369)$ a las 24 y $48 \mathrm{~h}$, respectivamente. El efecto del uso de SAGPI en el SSP también se evidenció mediante la comparación de todos los sustratos que incluyeron SAGPI en el SSP (SSP+ $\sum$ SAGPI) vs el SSP que no lo incluyó, encontrándose una menor producción de metano en $\mathrm{SSP}+\sum \mathrm{SAGPI}$ a las 24 y $48 \mathrm{~h}$ (Cuadro 4 ), 7,6\% y 8,8\% menos, respectivamente. Este resultado sugiere efectividad en la reducción de metano al utilizar SAGP3 o SAGP2 en SSP.

El efecto de la utilización de SAGPI fue mejor en las mezclas que representaron dietas de sistemas silvopastoriles, que aquellas que representaron los sistemas de monoculivo de pasto ( $\mathrm{SSP}+\sum \mathrm{SAGPI}$ vs MONO $+\sum$ SAGPI, Cuadro 4), encontrándose una reducción de metano del 8,9\% y 10,2\% a las 24 y a las 48 h, respectivamente. Estos resultados complementan los efectos ya mencionados de la inclusión de BO en las dietas. Cuando se compararon sustratos que representaron sistemas silvopastoriles más adición de SAGPI (S4, S5, S6), con el sustrato que representó una alimentación en un sistema de monocultivo de pasto kikuyo (S8) se encontró una menor producción de metano en los $\mathrm{SSP}+\sum \mathrm{SAGPI}(\mathrm{p}<0,05)$ (Cuadro 3).

El sustrato SSP+SAGPI1 (S4) vs MONO (S8) redujo la producción de metano en un 31,84\% y 33,0\% a las 24 y 48 h, respectivamente; SSP + SAGPI2 (S5) vs MONO (S8) lo redujo 37,81\% y 39,24\% a las 24 y 48 h, respectivamente; y SSP + SAGPI3 (S6) vs MONO (S8) lo redujo 40,10\% y 41,75\% a las 24 y $48 \mathrm{~h}$, respectivamente. La comparación pre-planeada de SSP con $\Sigma$ SAGPI vs MONO (Cuadro 4), también arrojó diferencias estadísticas significativas a favor del primero ( $\mathrm{p}<0,05)$; se encontró una disminución de metano del 8,9\% y 12,2\% a las 24 y 48 h, respectivamente. Estos resultados evidencian un posible potencial para disminuir metano cuando se combina la acción de los metabolitos secundarios del BO y la de SAGPI, tema hasta ahora muy poco explorado.

\section{Degradabilidad in vitro de la materia seca (DIVMS) y factor de partición (FP)}

Hubo diferencia estadística significativa entre sustratos para el \% DIVMS en los intervalos 0-24 y 0-48 horas $(\mathrm{p}<0,05)$ (Cuadro 5); también se encontraron diferencias significativas entre horarios de medición e interacción significativa entre sustrato y horario de medición $(\mathrm{p}<0,05)$; asimismo, las comparaciones pre-planeadas realizadas

mostraron diferencias estadísticas significativas. En el FP se encontró efecto significativo del sustrato y del horario de medición $(\mathrm{p}<0,05)$.

\section{Efecto del sustrato}

El botón de oro (T1) tuvo un mayor \%DIVMS respecto al kikuyo (T7) $(\mathrm{p}<0,05)$ en ambos horarios de medición (Cuadro 5); se encontró un 13,4\% y un 7,7\% más de \%DIVMS con solo BO a las 24 y a las 48 h, respectivamente (Cuadro 5). Los valores de \%DIVMS encontrados en el presente trabajo para BO fueron similares a los reportados por Mahecha y Rosales (2005) a las 48 h (63,3\%) en una prueba de degradabilidad in sacco. Incluso se han encontrado valores de \%DIVMS de esta forrajera hasta del 83 y $90 \%$ a las 24 y 48 h de incubación in vitro (Rosales, 1996). La comparación del sustrato que contenía BO+kikuyo+alimento concentrado+grasa saturada protegida (S3) vs el mismo sustrato sin BO (S8), alcanzó un 5,18\% más en el \%DIVMS a las 24 h y un 2,5\% más a las 48 h, pero 
Cuadro 5. Interacción entre los once sustratos empleados para estimar la degradabilidad in vitro de la materia seca (\% DIVMS) en dos intervalos de tiempo, en vacas holstein. Medellín, Colombia. 2016.

Table 5. Interaction between the eleven substrates used to estimate the in vitro degradability of dry matter (\% IVDMD) in two time intervals, in Holstein cows. Medellin, Colombia. 2016.

\begin{tabular}{|c|c|c|c|c|c|c|c|c|c|c|c|c|c|c|c|c|c|c|c|c|c|}
\hline Variable & & 1 & S & 2 & & 3 & S & 4 & $\mathrm{~S}$ & 5 & S & 6 & & 87 & & 88 & S & & S1 & 10 & S11 \\
\hline Horario & 24 & 48 & 24 & 48 & 24 & 48 & 24 & 48 & 24 & 48 & 24 & 48 & 24 & 48 & 24 & 48 & 24 & 48 & 24 & 48 & 24 \\
\hline$\%$ & 59,1 & 65,1 & 56,5 & 61,1 & 55,9 & 64,6 & 57,6 & 64,9 & 59,6 & 67,2 & 60,1 & 68,2 & 51,2 & 60,1 & 53 & 63 & 55,5 & 64,2 & 56,7 & 63,4 & $57,7 \quad 65,1$ \\
\hline DIVMS & $\mathrm{T}$ & S & ñprt & $\begin{array}{l}\text { no } \\
\text { qs }\end{array}$ & $\begin{array}{c}\mathrm{m} \tilde{n} \\
\mathrm{pr}\end{array}$ & $\begin{array}{c}\text { lno } \\
\text { qs }\end{array}$ & $\begin{array}{c}\text { Kmñ } \\
\text { prt }\end{array}$ & $\begin{array}{c}\text { Jlno } \\
\text { qs }\end{array}$ & $\begin{array}{c}\text { iknñ } \\
\text { prt }\end{array}$ & $\begin{array}{l}\text { Hjl } \\
\text { oqs }\end{array}$ & $\begin{array}{l}\text { Gik } \\
\text { npt }\end{array}$ & fhos & E & $\begin{array}{l}\text { Dagi } \\
\text { knopt }\end{array}$ & $\begin{array}{c}\mathrm{Ce} \\
\mathrm{m}\end{array}$ & $\begin{array}{c}\text { acjl } \\
\text { noqs }\end{array}$ & $\begin{array}{l}\text { bck } \\
\text { mñpr }\end{array}$ & $\begin{array}{c}\text { ahjln } \\
\text { oqs }\end{array}$ & $\mathrm{rt}$ & qs & prt \\
\hline
\end{tabular}

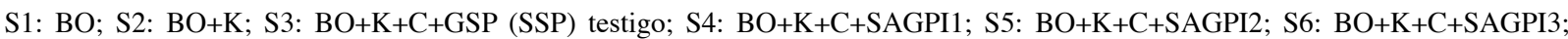
S7: K; S8: K+C+GSP (MONO) testigo; S9: K+C+SAGPI1; S10: K+C+SAGPI2; S11: K+C+SAGPI3; BO: botón de oro; DIVMS: degradabilidad in vitro materia seca; S: sustrato / S1: BO; S2: BO + K; S3: BO + K + C + GSP (SSP) control; S4: BO + K + C + SAGPI1; S5: BO + K + C + SAGPI2; S6: BO + K + C + SAGPI3; S7: K; S8: K + C + GSP (MONO) control; S9: K + C + SAGPI1; S10: K + C + SAGPI2; S11: K + C + SAGPI3; BO: wild sunflower; DIVMS: dry matter in vitro degradability; S: substrate.

Medias con diferente letra en la fila presentan diferencia estadística significativa $(\mathrm{p}<0,05)$ / Means with different letter in a row show a statistically significant difference $(\mathrm{p}<0.05)$.

las diferencias no fueron estadísticamente significativas ( $>00,05)$; estos resultados (Cuadro 5) fueron superiores a los informados por Rivera et al. (2013), quienes encontraron un \%DIVMS para la mezcla de BO, pasto y suplemento para bovinos de 36,7 y $57,9 \%$ a las 24 y 48 h de incubación respectivamente.

Sin embargo, al hacer la comparación de todos los sustratos que incluyeron BO, se encontró un mayor \%DIVMS a las $24 \mathrm{~h}$ de incubación (> 5,7\%), en comparación con aquellos sustratos que no incluyeron la forrajera $(\mathrm{p}<0,05)$, pero a las $48 \mathrm{~h}$ fueron estadísticamente iguales $(\mathrm{P}>0,05)$ (Cuadro 6). Al igual que en la presente investigación, Rivera et al. (2013) encontraron que en dietas para bovinos que contenían BO, el mayor \%DIVMS se presentó hasta el horario de las $24 \mathrm{~h}$, lo que posiblemente se deba a la rápida degradación de la fracción proteica y de los carbohidratos solubles del BO en el líquido ruminal (Mahecha y Rosales, 2005).

El BO ha demostrado ser una forrajera con potencial en la alimentación de rumiantes, debido a su alta aceptabilidad y buen nivel de proteína (Gualberto et al., 2010). Según Ekeocha (2012), la harina de BO parece adecuada para usarse como concentrado proteico en rumiantes, y podría ser un buen sustituto de materias primas como el salvado de trigo, debido a sus aceptables niveles de fibra y extracto libre de nitrógeno (ELN), de donde el animal podría obtener parte de la energía que requiere. En el presente experimento, el BO utilizado como sustrato contenía un $17,2 \%$ de PC y un $29,5 \%$ de ELN (Cuadro 1), estos valores sugieren un impacto positivo en la nutrición de vacas lecheras, ya que probablemente los aminoácidos y péptidos liberados por la especie forrajera a nivel ruminal, sumado al aporte energético, podrían mejorar la eficiencia microbiana en la síntesis proteica y la digestibilidad en bovinos (Medina et al., 2009).

Estos resultados a su vez podrían indicar que la inclusión de forrajeras como el BO capaces de aportar buenas fuentes de proteína y carbohidratos solubles (sincronía nitrógeno-energía) a los microorganismos del rumen, específicamente a los celulolíticos, podría favorecer la degradación de la fibra, alta fermentabilidad de la materia seca y por lo tanto, una más rápida disponibilidad de los nutrientes productos de la fermentación (Mahecha y Rosales, 2005; La O et al., 2012). Adicionalmente, Naranjo y Cuartas (2011) consideraron que el BO presenta un buen balance entre proteína y compuestos fibrosos. Respecto al incremento de la degradabilidad en mezclas de $\mathrm{BO}$ y gramíneas, Galindo et al. (2011) al incluir hasta el 20\% de esta forrajera en dietas con pasto estrella (Cynodon nlemfuensis), encontraron un aumento en la población de organismos celulolíticos, según los autores, se demostró el beneficio del forraje para mejorar la fermentación microbiana ruminal y a la vez, una notable reducción de 
Cuadro 6. Comparaciones utilizadas para contrastar la digestibilidad de la materia seca (\%DIVMS) y la relación entre la materia seca digestible y el volumen de gas (MSD/VG mg/ml) entre distintos grupos de sustratos, con la inclusión de botón de oro y/o fuentes de ácidos grasos poliinsaturados (AGPI), en dos intervalos de tiempo, en vacas holstein. Medellín, Colombia, 2016.

Table 6. Comparisons used to contrast the dry matter digestibility (\%DIVMS) and the relationship between the dry matter digestibility and the volume of gas (MSD/VG mg/ml) among different groups of substrates including wild sunflower and/ or polyunsatured fatty acids (AGPI) sources, in two time intervals, in Holstein cows. Medellin, Colombia, 2016.

\begin{tabular}{|c|c|c|c|c|c|c|c|c|c|c|c|}
\hline \multirow[b]{2}{*}{ Variable } & \multirow[b]{2}{*}{$\begin{array}{c}\text { Intervalo } \\
\text { horas }\end{array}$} & \multicolumn{2}{|c|}{$\begin{array}{c}\text { SSP+ }+\sum \text { SAGPI vs } \\
\text { MONO }+\sum S A G P I\end{array}$} & \multicolumn{2}{|c|}{$\begin{array}{c}\text { SSP vs } \\
\text { SSP+ }+\sum \text { SAGPI }\end{array}$} & \multicolumn{2}{|c|}{$\begin{array}{c}\text { MONO vs } \\
\text { MONO+ }+\sum \text { SAGPI }\end{array}$} & \multicolumn{2}{|c|}{$\begin{array}{c}\text { MONO vs } \\
\text { SSP+ }+\sum \text { SAGPI }\end{array}$} & \multicolumn{2}{|c|}{$\begin{array}{c}\text { Sust con BO vs Sust } \\
\sin B O\end{array}$} \\
\hline & & SSP & $\begin{array}{c}\text { SSP+ } \\
\sum A G P I\end{array}$ & MONO & $\begin{array}{c}\text { MONO+ } \\
\Sigma A G P I\end{array}$ & $\begin{array}{c}\text { SSP+ } \\
\sum A G P I \\
\end{array}$ & $\begin{array}{c}\text { MONO+ } \\
\sum \text { AGPI }\end{array}$ & MONO & $\begin{array}{c}\text { SSP+ } \\
\sum \text { AGPI }\end{array}$ & $\begin{array}{l}\text { Sust con } \\
\text { BO }\end{array}$ & $\begin{array}{c}\text { Sust sin } \\
\text { BO }\end{array}$ \\
\hline \multirow[t]{2}{*}{$\%$ DIVMS } & 24 & $55,8 \mathrm{a}$ & $59,1 \mathrm{a}$ & $53 b$ & $56,6 \mathrm{a}$ & $59,1 \mathrm{a}$ & $52,6 \mathrm{~b}$ & $53 b$ & $59,1 \mathrm{a}$ & $58,1 \mathrm{a}$ & $54,8 \mathrm{~b}$ \\
\hline & 48 & $64,6 a$ & $66,8 \mathrm{a}$ & $63 b$ & $64,6 \mathrm{a}$ & $66,8 \mathrm{a}$ & $64,6 \mathrm{~b}$ & $63 b$ & $66,8 \mathrm{a}$ & $65,4 a$ & $63,4 \mathrm{a}$ \\
\hline $\mathrm{MSD} / \mathrm{VG}$ & 24 & $4,6 \mathrm{~b}$ & $5,4 \mathrm{a}$ & $3,2 \mathrm{~b}$ & $4,5 \mathrm{a}$ & $5,4 a$ & $4,5 \mathrm{~b}$ & $3,2 \mathrm{~b}$ & $5,4 \mathrm{a}$ & $5,9 \mathrm{a}$ & $4,3 \mathrm{~b}$ \\
\hline $\mathrm{mg} / \mathrm{ml}$ & 48 & $4,3 b$ & $4,8 \mathrm{a}$ & $2,9 b$ & $4,3 \mathrm{a}$ & $4,8 \mathrm{a}$ & $4,3 b$ & $2,9 b$ & $4,8 \mathrm{a}$ & $4,5 \mathrm{a}$ & $3,9 b$ \\
\hline
\end{tabular}

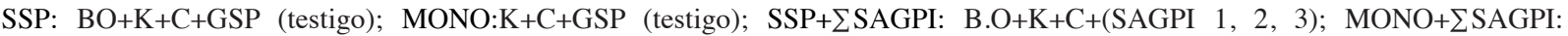
$\mathrm{K}+\mathrm{C}+(\mathrm{SAGPI}$ 1, 2, 3); BO: botón de oro; DIVMS: degradabilidad in vitro materia seca; MSD: materia seca degradada; VG: volumen de gas; Sust: sustrato / SSP: BO + K + C + GSP (control); MONO: GSP + K + C (control); SSP + 5 SAGPI: B.O + K + C + (SAGPI $1,2,3) ;$ MONO + $\Sigma$ SAGPI: $\mathrm{K}+\mathrm{C}+($ SAGPI 1,2,3); BO: wild sunflower; DIVMS: dry matter in vitro degradability ; MSd: degraded dry matter; VG: gas volume; Sust: substrate.

Medias con diferente letra en la fila presentan diferencia estadística significativa $(p<0,05)$ / Means with different letter in a row show a statistically significant difference $(\mathrm{p}<0.05)$.

bacterias metanogénicas, lo que sugiere que la combinación de BO y gramíneas tropicales podría ser también una opción para disminuir la contaminación ambiental.

La utilización de fuentes de ácidos grasos poliinsaturados (SAGPI) en el MONO mejoró significativamente el \%DIVMS a las $24 \mathrm{~h}$; los sustratos S10 (K+C+SAGPI2) y S11 (K+C+SAGPI3) tuvieron un mayor \%DIVMS al compararlos con el sustrato S8 que no incluía SAGPI (K+C+grasa saturada protegida) (Cuadro 5). Igualmente, la comparación planeada que incluía la sumatoria de SAGPI en el MONO también evidenció un aumento en el \%DIVMS (Cuadro 6). El \%DIVMS fue similar en el SSP con o sin utilización de SAGPI tanto a las 24 como a las 48 h. Referente al tipo de grasa utilizada en la suplementación de rumiantes, varios autores argumentan que las fuentes de grasa protegidas tienen poco o ningún efecto sobre la degradabilidad de la dieta (Cruywagen et al, 2003; Hashem y Harb, 2006; Gagliostro y Schroeder, 2007).

Niveles de AGPI hasta de 4,5\% no han mostrado reducción en cuanto a la digestibilidad ruminal de la fibra (Avila et al., 2000; Montgomery et al., 2008). Vafa et al. (2009) incluyeron 2\% de aceite de pescado en dietas para rumiantes; la dieta redujo significativamente la digestibilidad de la ración de 57,8 a 50,6\%, pero no hubo diferencias cuando se administró $1 \%$ de aceite de pescado combinado con $1 \%$ de aceite de colza, lo que los autores atribuyen a un efecto positivo en la combinación de las fuentes de aceites. Se considera que la inclusión de niveles $>6-7 \%$ de grasa total en la dieta de bovinos como porcentaje de la MS, tiene efectos negativos sobre la digestibilidad de la fibra en rumen, los cuales están asociados con la inhibición de la actividad de los microorganismos celulolíticos (Harfoot y Hazlewood, 1997; NRC, 2001; Arenas et al., 2010).

El efecto negativo de la inclusión de fuentes de ácidos grasos insaturados no protegidos en la dieta para rumiantes sobre la digestibilidad de la fibra, es improbable cuando el aporte de este tipo de grasa no supera el $4 \%$ (Martínez et al., 2011). En concordancia con lo anterior, en el presente estudio la inclusión de SAGPI en cada uno de los sustratos fue máximo el 3\% de la MS, por lo que se esperaba que la degradabilidad de la MS no se deprimiera. Adicionalmente, varios autores han relacionado los cambios en la degradabilidad de la MS in vitro, con el perfil 
de microorganismos ruminales, el cual puede llegar a variar dependiendo la fuente y nivel de inclusión de ácidos grasos poliinsaturados en la dieta (Kongmun et al., 2011; Liu et al., 2011; 2012). Además, aceites como el de coco, girasol y pescado se han relacionado con la disminución del número de bacterias tipo gram negativas y estabilidad en bacterias gram positivas como Ruminococcus ssp., R. albus y R.flavefaciens, relacionadas con el aumento en la degradación de la fibra en pruebas de digestibilidad y perfil de microorganismos ruminales (Kongmun et al., 2011; Liu et al., 2011; 2012).

Al determinar los efectos de la inclusión de ácidos grasos poliinsaturados $>20$ carbonos (AGPI), sobre microorganismos ruminales asociados a la digestión de la fibra, Liu et al. (2012) encontraron que en dietas para bovinos (65:forraje, 35:alimento concentrado) al adicionar $2 \%$ aceite de girasol y $2 \%$ de aceite de pescado, aumentó el número de bacterias del tipo Anerovibrio lipolytica en un 5,38\% en comparación con la dieta sin adición de dichos aceites. La Anerovibrio lipolytica juega un papel fundamental en la hidrólisis de los triglicéridos y algunos restos de azúcares de la dieta a nivel ruminal, originando ácidos grasos libres, glicerol y monómeros de azúcar, los cuales podrían ser utilizados por el resto de poblaciones bacterianas a nivel ruminal como fuente de energía (Harfoot y Hazlewood, 1997).

$\mathrm{Al}$ evaluar varios tratamientos que incluían heno de Tifton 85 con adición de $80 \mathrm{~g} / \mathrm{kg}$ MS de aceite de soya y heno de Tifton 85 con adición de 80 g/kg MS de aceite de linaza más la adición de 0 o 150 g/kg MS de glicerol, se encontró un aumento significativo de 33 y $13 \%$ en la población de Anaerovibrio lipolityca al incluir en las dietas 150 $\mathrm{g} / \mathrm{kg}$ MS de glicerol, sin afectarse la degradabilidad de la materia seca (Castagnino, 2014). El mantenimiento de la degradabilidad fue asociado a que no se presentó disminución de bacterias fibrolíticas totales, pero sí una tendencia al aumento de especies como Ruminococcus albus, Ruminococcus flavefaciens y subgrupos de Butyrivrio, las cuales inciden positivamente en la degradación de la fibra a nivel ruminal. En este trabajo el autor también reportó disminución en la producción de metano y en la proporción de bacterias metanogénicas, atribuyendo la disminución de metano probablemente a la utilización del $\mathrm{H}_{2}$ como sustrato para la conversión de propionato a partir de glicerol y no de $\mathrm{CH}_{4}$, y al efecto tóxico de los AGPI sobre la membrana de los microorganismos metanogénicos.

Varios estudios, al igual que en la presente investigación, han encontrado aumento de la digestibilidad de la fibra al incluir fuentes de AGPI en dietas para rumiantes, al respecto, Doreau y Chilliard (1997) al utilizar cantidades de hasta $400 \mathrm{ml} /$ día de aceite de pescado vía oral en vacas lecheras, encontraron aumento $(\mathrm{p}<0,01)$ de la degradabilidad de la fibra orgánica y del propionato a nivel ruminal; también relacionaron la adición de fuentes de AGPI como el aceite de pescado, con una acción específica sobre el metabolismo y/o naturaleza de los microorganismos involucrados en la digestión de la fibra, al aumentar aquellas poblaciones de microorganismos que producen propionato a partir de succinato como Selenomonas ruminantium o Bacteroides succinogenes.

El incremento en la digestibilidad de la ración al incluir fuentes de ácidos grasos poliinsaturados, también ha sido reportado por Amorocho et al. (2009), quienes al adicionar aceite de pescado en dietas basadas en ensilaje de maíz para vacas lecheras, encontraron aumento de la digestibilidad ruminal de la FDN. En investigaciones donde se mezclaron fuentes de aceites poliinsaturados, como el de soya y saponinas extraídas de Sesbania pachycarpa, se aumentó la población de la especie Ruminococus y estabilidad de la fermentación de la fibra con la subsecuente disminución de hasta $20 \%$ en la producción de metano a nivel ruminal (Muetzel et al., 2003; Wina et al., 2005; Zang et al., 2008).

Finalmente, cuando se contrastaron las comparaciones que representaron sistemas silvopastoriles más SAGPI ( $\mathrm{S} 4=\mathrm{SSP}+\mathrm{SAGPI} 1, \mathrm{~S} 5=\mathrm{SSP}+\mathrm{SAGP} 2, \mathrm{~S} 6=\mathrm{SSP}+\mathrm{SAGP} 3)$ vs el MONO ( $8=\mathrm{K}+\mathrm{C}+\mathrm{GSP})$ que representó un sistema de monocultivo de pasto kikuyo, se presentó diferencia estadística $(\mathrm{P}<0,05)$ entre ambos a favor de los sustratos SSP. Igualmente, en la comparación planeada que incluía la sumatoria de todos los SAGPI (SSP $+\sum$ SAGPI vs MONO) se presentó aumento en el \%DIVMS de 10,3 y 5,7\% a las 24 y 48 h de incubación, respectivamente (Cuadro 6). Estos resultados sumados a los de producción de metano, ratifican la combinación SSP + SAGPI como una estrategia para la disminución de la producción de metano sin detrimento del \%DIVMS. 


\section{Factor de partición (FP)}

Generalmente, sustratos que registren mayor degradación de la MS por unidad de gas generado, se asocian con mayores FP y formación de biomasa microbiana, pero con diminución en la producción de metano (Posada y Noguera, 2005). Al igual que reporta Blümmelt et al. (1999), en este trabajo, el FP disminuyó con el tiempo de incubación, de tal forma que la producción de gas o de ácidos grasos volátiles (AGV) y de biomasa microbiana por unidad de sustrato realmente degradado, no es una constante y una relación inversa podría existir entre ellos.

En la presente investigación los FP (Cuadro 6) fueron estadísticamente diferentes $(\mathrm{p}<0,05)$ entre todas las comparaciones en ambos horarios, los grupos de tratamientos que incluyeron BO y/o la adición de AGPI presentaron mayores FP. Así por ejemplo, al comparar los tratamientos que contenían BO vs los que no contenían la forrajera, el primer grupo presentó un 27\% y 13\% más de FP en los horarios de las 24 y 48 h de incubación. Los anteriores resultados coinciden con lo obtenido por Rivera et al. (2013), quienes al evaluar varios forrajes y mezclas de forrajes más suplemento para bovinos lecheros de trópico alto, encontraron que los FP fueron mayores $(\mathrm{p}<0,05)$ para el $\mathrm{BO}$ y las mezclas que incluyeron esta forrajera. Al contrastar la comparación entre lo que equivale a un sistema de monocultivo con kikuyo MONO (K+C+GSP) y un SSP, más la adición de SAGPI (SSP+SAGPI), el SSP presentó un aumento $(\mathrm{p}<0,05)$ del 40,7\% y del 39,6\% en el FP a las 24 y $48 \mathrm{~h}$, respectivamente, frente al MONO.

El aumento del FP en los tratamientos que incluyeron BO y/o utilización de SAGPI, le proporcionó un importante valor agregado a estas dietas, ya que se ha reportado que las raciones que pretendan ser más sustentables desde el punto de vista ambiental (menor producción de metano), deben mostrar mayores FP. Lo anterior también impacta positivamente el consumo de materia seca, lo cual las hace más competitivas nutricionalmente (Posada y Noguera, 2005).

\section{Producción total y proporción molar de AGV}

En el presente estudio en todos los grupos de sustratos se produjo mayor producción de AGV (mmol/l) en el horario de las $48 \mathrm{~h}$ respecto al de $24 \mathrm{~h}$ (Cuadro 7); esto se debió probablemente a que en la técnica in vitro de producción de gases no existe remoción de AGV vía absorción, por lo que, su concentración depende de la tasa de fermentación y puede incrementarse gradualmente (Ramírez et al., 2015a; 2015b). Se presentó diferencia estadística $(\mathrm{p}<0,05)$ en el total de AGV, al comparar los grupos de sustratos que incluían BO vs los que no incluyeron BO a las 24 h de incubación; en este horario los sustratos con inclusión de BO presentaron un 10,6\% más de AGV totales; pero a las $48 \mathrm{~h}$ los sustratos sin BO produjeron un 5,4\% más de AGV totales. La posible producción de mayor cantidad de AGV a las $24 \mathrm{~h}$ al incluir $\mathrm{BO}$, pudo deberse a una más rápida degradación del $\mathrm{BO}$ en el inóculo ruminal, ya que el aporte de nutrientes de rápida fermentación como azúcares y proteínas solubles, podría conllevar a una formación más rápida de AGV (Gallego et al., 2014).

Se ha reportado que en dietas donde haya un sustrato que aporte buena energía durante las primeras $24 \mathrm{~h}$ de fermentación, generalmente se presenta un aumento en la proporción de AGV, el cual puede disminuir en posteriores horas, debido a que es posible que los microorganismos degraden los AGV para obtener energía (Wang et al., 1999). De manera general, en los resultados de este estudio, el porcentaje de AGV totales a las 24 h de incubación, aumentó con la adición de fuentes de ácidos grasos poliinsaturados (AGPI) (3\% MS). Al contrastar el sistema SSP con SSP+SAGPI, este último aumentó 15,4\% la producción de AGV respecto al primero, y en el MONO vs MONO+SAGPI se incrementó 8\% el total de AGV respecto a la no adición de la fuente lipídica insaturada. Al comparar el tratamiento equivalente a un sistema tradicional de pastoreo con kikuyo MONO $(\mathrm{K}+\mathrm{C}+$ GSP) vs el grupo de tratamientos que simuló un sistema silvopastoril más adición de SSP+ $\sum$ SAGPI, se encontró un aumento del $11,4 \%$ de AGV totales a las 24 h de medición en el SSP+ $\sum$ SAGPI (p>0,05) (Cuadro 7). 
Cuadro 7. Comparaciones utilizadas para contrastar la concentración total y proporción de ácidos grasos volátiles (AGV) producto de la fermentación in vitro entre distintos grupos de sustratos con la inclusión de botón de oro y/o fuentes de ácidos grasos poliinsaturados (AGPI), en dos intervalos de tiempo, en vacas holstein. Medellín, Colombia. 2016.

Table 7. Comparisons used to contrast the total concentration and ratio of volatile fatty acids (VFA) product of in vitro fermentation between different groups of substrates, including wild sunflower and/or sources of polyunsatured fatty acids (AGPI), in two time intervals, in Holstein cows. Medellin, Colombia. 2016.

\begin{tabular}{|c|c|c|c|c|c|c|c|c|c|c|c|c|c|}
\hline \multirow[b]{2}{*}{ Variable } & \multirow[b]{2}{*}{$\begin{array}{c}\text { Intervalo } \\
\text { horas }\end{array}$} & \multicolumn{2}{|c|}{ SSP vs MONO } & \multicolumn{2}{|c|}{$\begin{array}{c}\text { SSP vs } \\
\text { SSP+ }+\sum \text { AGPI }\end{array}$} & \multicolumn{2}{|c|}{$\begin{array}{c}\text { MONO vs } \\
\text { MONO+ }+\sum \text { AGPI }\end{array}$} & \multicolumn{2}{|c|}{$\begin{array}{l}\text { SSP+ } \sum \text { AGPI vs } \\
\text { MONO+ }+\sum A G P I\end{array}$} & \multicolumn{2}{|c|}{$\begin{array}{c}\text { MONO vs } \\
\text { SSP }+\sum A G P I\end{array}$} & \multicolumn{2}{|c|}{$\begin{array}{l}\text { Sust con B.O vs } \\
\text { Sust } \sin \text { B.O }\end{array}$} \\
\hline & & SSP & MONO & SSP & $\begin{array}{c}\text { SSP+ } \\
\sum \text { AGPI }\end{array}$ & MONO & $\begin{array}{c}\text { MONO+ } \\
\sum \text { AGPI }\end{array}$ & $\begin{array}{c}\text { SSP } \\
\sum \text { AGPI }\end{array}$ & $\begin{array}{c}\text { MONO+ } \\
\sum \text { AGPI }\end{array}$ & MONO & $\begin{array}{c}\text { SSP + } \\
\sum \text { AGPI }\end{array}$ & $\begin{array}{c}\text { Sust con } \\
\text { B.O }\end{array}$ & $\begin{array}{c}\text { Sust sin } \\
\text { B.0 }\end{array}$ \\
\hline \multirow{3}{*}{$\begin{array}{l}\text { Total AGV } \\
(\mathrm{mmol} / \mathrm{l})\end{array}$} & 24 & 145,8 & 152,7 & $145,8 b$ & $172,3 \mathrm{a}$ & $152,7 b$ & $166^{\mathrm{a}}$ & $172,3 \mathrm{a}$ & $166 b$ & $152,7 \mathrm{~b}$ & $172,3 \mathrm{a}$ & $177,8 \mathrm{a}$ & $158,8 b$ \\
\hline & 48 & 281,8 & 302,1 & 281,8 & 274 & 302,1 & 281,8 & 274 & 281 & 302,1 & 274 & $255,6 b$ & $270,24 a$ \\
\hline & \multicolumn{13}{|c|}{ Proporción molar AGV (\% molar) } \\
\hline \multirow[t]{2}{*}{$\%$ acético } & 24 & 73,6 & 73,2 & 73,6 & 70,3 & 73,2 & 74 & $70,3 b$ & $74 a$ & 73,2 & 70,3 & 72,7 & 74,7 \\
\hline & 48 & 74 & 70 & 74 & 72,8 & 70 & 71,6 & 72,8 & 71,6 & 70 & 72,8 & 72,8 & 71,6 \\
\hline \multirow[t]{2}{*}{ \% butírico } & 24 & $7,8 \mathrm{~b}$ & $11 \mathrm{a}$ & $7,8 \mathrm{~b}$ & $10,6 \mathrm{a}$ & $11,6 \mathrm{a}$ & $8,5 b$ & $10,6 \mathrm{a}$ & $8,5 b$ & 11 & 10,6 & 9,1 & 8,8 \\
\hline & 48 & 6,9 & 8,5 & $6,9 \mathrm{~b}$ & $10 \mathrm{a}$ & 8,5 & 8,7 & 10 & 8,7 & 8,5 & 10 & 8,7 & 8,3 \\
\hline \multirow{2}{*}{$\begin{array}{l}\% \\
\text { propiónico }\end{array}$} & 24 & 18,5 & 15,2 & 18,5 & 19 & 15,2 & 17,4 & 19 & 17,5 & $15,2 b$ & $19 \mathrm{a}$ & 18,1 & 16,5 \\
\hline & 48 & 19 & 21,4 & 19 & 19,8 & 21,4 & 19,8 & 19,8 & 19,8 & 19 & 19,8 & 18,5 & 20 \\
\hline
\end{tabular}

SSP: B.O+K+C+GSP (testigo); MONO:K+C+GSP (testigo); SSP+ $\sum$ SAGPI: B.O+K+C+(SAGPI 1, 2, 3); MONO+ $\Sigma$ SAGPI: $\mathrm{K}+\mathrm{C}+(\mathrm{SAGPI} 1,2,3)$; B .O: botón de oro; AGV: ácidos grasos volátiles; Sust: sustrato / SSP: BO + K + C + GSP (control); MONO: K +

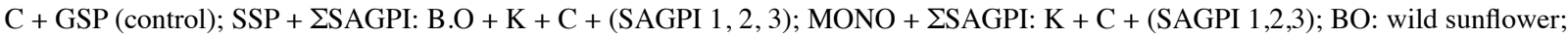
AGV: volatile fatty acids; Sust: substrate.

Medias con diferente letra en la fila presentan diferencia estadística significativa $(p<0,05) /$ Means with different letter in a row show a statistically significant difference $(\mathrm{p}<0.05)$.

Al igual que en la presente investigación, Jacob et al. (2012) no encontraron disminución en el total de AGV al adicionar aceite de soya en proporciones de 4,5\% de la MS en dietas para bovinos, pero si encontraron una disminución significativa sobre los AGV, al aumentar la dosis de aceite a niveles del $6 \%$ de la MS. Asimismo, Benchaar et al. (2012) suplementaron con una fuente de AGPI (aceite de lino) en niveles de hasta 4\% de la MS, en una ración totalmente mezclada, y tampoco encontraron disminución del total de AGV. El nivel y la fuente de inclusión de lípidos determinan en gran medida los productos de la fermentación ruminal entre ellos la proporción de AGV (Toral et al., 2009).

La proporción molar de AGV (\% molar) en todos los grupos de sustratos evaluados en ambos periodos de medición, fueron en su orden: acético $(73 \% 24 \mathrm{~h} ; 72,1 \% 48 \mathrm{~h}$ ), propiónico $(17,5 \% 24 \mathrm{~h} ; 19,8 \% 48 \mathrm{~h})$, butírico $(9,4 \% 24$ h; 8,5\% 48 h). La mayor fermentación fue acética, debido probablemente a que la mayor proporción en las mezclas fue de forraje (mínimo 57\% kikuyo). En relación con lo anterior, Rodríguez et al. (2009), reportaron que el perfil de AGV se modifica básicamente por el tipo de dieta, la relación forraje:alimento concentrado, el nivel de consumo y el empleo de aditivos, entre otros; según los autores, el aumento de fuentes fibrosas generalmente conlleva a fermentación acética.

La proporción molar de cada AGV (>acético>propiónico>butírico), coincidió con lo reportado por Marín et al. (2014), quienes al evaluar in vitro la producción de AGV del pasto kikuyo encontraron la misma proporción molar. Asimismo, coincidió con lo reportado por Marín (2013) al evaluar mezclas de kikuyo:alimento concentrado en proporción 70:30, y Cieslak et al. (2013), que al evaluar dietas para bovinos con proporciones de $60 \%$ forraje 
y 30\% suplemento energético, más la adición de aceites de frutas como fuente de AGPI, ricos en ácido linoléico, encontraron que las proporciones de acético fueron mayores, debido a la mayor inclusión de forraje, seguidos por una fermentación propiónica y butírica, respectivamente.

\section{Conclusiones}

En estudios in vivo al incluir en la dieta base para bovinos, forrajeras tradicionales como el $\mathrm{BO}$ y la adición de niveles moderados AGPI, se podría esperar un mantenimiento de la productividad animal, basados en la eficiencia de la degradación ruminal de la MS y la disminución de emisiones de metano, tal como se ha demostrado en pruebas in vitro.

\section{Agradecimientos}

Los autores agradecen al proyecto "Fortalecimiento de la producción de la cadena láctea del distrito Norte Antioqueño", convenio N ${ }^{\circ}$ 2012AS180031, firmado entre la Secretaría de Agricultura y Desarrollo Rural del Departamento de Antioquia, la Universidad Nacional de Colombia (sede Medellín) y la Universidad de Antioquia, con recursos del Sistema General de Regalías- SGR, por el apoyo económico para ejecutar este trabajo.

\section{Literatura citada}

Amorocho, A., T. Jenkins, and C. Staples. 2009. Evaluation of catfish oil as a feedstuff for lactating Holstein cows. J. Dairy Sci. 92:5178-5188.

Angarita, E.A. 2013. Efecto de la inclusión de un forraje tanífero sobre las poblaciones metanogénicas del ecosistema ruminal en condiciones in vitro e in vivo. Tesis MSc., Universidad Nacional de Colombia, Bogotá, COL.

AOAC (Association of Official Analytical Chemists). 1999. Official methods of analysis of AOAC International. 16 ${ }^{\text {th }}$ ed. AOAC Int., Gaithersburg, MD, USA.

Apráez, J., J.M. Delgado y J.P. Narváez. 2012. Composición nutricional, degradación in vitro y potencial de producción de gas, de herbáceas, arbóreas y arbustivas encontradas en el trópico alto de Nariño. Liv. Res. Rural Dev. 24(3). http://www.lrrd. org/lrrd24/3/apra24044.htm

Arcuri, P., F. Ferraz, e J. Carneiro. 2006. Microbiologia do rúmen. En: T.T. Berchielli, A.V. Pires, e S.G. Oliveira, editores, Nutrição de ruminantes. FUNEP, Sao Paulo, BRA. p. 111-150.

Arenas, F., R. Noguera, y L. Restrepo. 2010. Efecto de diferentes tipos de grasa en dietas. Rev. Colomb. Cienc. Pecu. 231:55-64.

Avila, C., E. DePeters, H. Perez-Monti, S. Taylor, and R. Zinn. 2000. Influences of saturation ratio of supplemental dietary fat on digestión and milk yield in dairy cows. J. Dairy Sci. 83:1505-1519.

Beauchemin, K.A., M. Kreuzer, F. O’Mara, and T.A. McAllister. 2008. Nutritional management for enteric methane abatement: a review. Aust. J. Exp. Agric. 48:21-27.

Benchaar, C., G. Romero-Pérez, P. Chouinard, F. Hassanat, M. Eugene, H. Petit, and C. Côrtes. 2012. Supplementation of increasing amounts of linseed oil to dairy cows fed total mixed rations: effects on digestion, ruminal fermentation characteristics, protozoal populations, and milk fatty acid composition. J. Dairy Sci. 95:4578-4590. 
Blümmel, M., A. Schröder, K. Südekum, and K. Becker.1999. Estimating ruminal microbial efficiencies in silage-fed cattle: comparison of an in vitro method with a combination of in situ and in vivo measurements. J. Anim Physiol. Anim. Nutr. 81:57-67.

Cambra, M., P. García, y F. Torres. 2008. Estimación de las emisiones de los rumiantes en España: el factor de conversión de metano. Arch. Zootec. 57:89-101

Carmona, J.C., D.M. Bolívar, y L.A. Giraldo. 2005. El gas metano en la producción ganadera y alternativas para medir sus emisiones y aminorar su impacto a nivel ambiental y productivo. Rev. Col. Cienc. Pecu. 18:49-63.

Castagnino,P.2014.In vitro fermentation parameters and biohydrogenation of vegetable oils without glycerol.MSc.Thesis,Estadual Paulista "Júlio de Mesquita Filho" University. http://repositorio.unesp.br/bitstream/handle/11449/113760/000803371. pdf?sequence $=1$ (accessed 12 jun. 2016).

Chavan, U., F. Shahidi, and M. Naczk. 2001. Extraction of condensed tannins from beach pea (Lathyrus maritimus L.) as affected by different solvents. Food Chem. 75:509-512.

Cieslak, A., Z. Varadyova, S. Kisidayova, D. Jalc, and M. Szumacher-Strabel. 2013. Effect of diets with fruit oils supplements on rumen fermentation parameters, fatty acid composition and methane production in vitro. J. Anim. Feed Sci. 22:26-34.

Cieslak, A., P. Zamora, E. Pers-Kamczyc, and M. Szumacher-Strabel. 2012. Effects of tannins source (Vaccinium vitis-idaea L.) on rumen microbial fermentation in vivo. Anim. Feed Sci. Technol. 176:102-106.

Cruywagen, C., E. Lategan, and L. Hoffman. 2003. The effect of rumen inert fat supplementation and protein degradability in starter and finishing diets on veal calf performance. SA J. Anim. Sci. 33:257-265.

Delgado, D., J. Galindo, R. González, N. González, I. Scull, L. Dihigo, J. Cairo, A. Aldama, and O. Moreira. 2012. Feeding of tropical trees and shrub foliages as a strategy to reduce ruminal methanogenesis: studies conducted in Cuba. Trop. Anim. Prod. 44:1097-1104.

Demeyer, D., et V. Fievez. 2000. Ruminants et environnement: la méthanogenèse. Ann. Zootech. 49:95-112. doi:10.1051/ animres:2000110

Deppenmeier, U., and V. Müller. 2008. Life close to the thermodynamic limit: how methanogenic archaea conserve energy. Results Probl. Cell. Differ. 45:123-152.

Doreau, M., and Y. Chilliard. 1997. Digestion and metabolism of dietary fat in farm animals. Br. J. Nutr. 1:15-35.

Ekeocha, A. 2012. Performance of growing west african dwarf ewe fed mexican sunflower leaf meal based diets. J. Rec. Adv. Agri. 1:69-76.

FAO. 2009. La larga sombra del ganado, problemas ambientales y opciones. http://www.fao.org/docrep/011/a0701s/a0701s00. htm (consultado 10 jun. 2016).

Fievez, V., F. Dohmeb, M. Danneels, K. Raes, and D. Demeyer. 2003. Fish oils as potent rumen methane inhibitors and associated effects on rumen fermentation in vitro and in vivo. Anim. Feed Sci. Technol. 104:41.

Fievez, V., B. Vlaeminck, T. Jenkins, T. Enjalbert, and M. Doreau. 2007. Assessing rumen biohydrogenation and its manipulation in vivo, in vitro and in situ. Eur. J. Lipid Sci. Technol. 109:740-756.

Gagliostro, G., y G. Schroeder. 2007. Efectos de la suplementación con sales cálcicas de ácidos grasos insaturados sobre la digestión ruminal en vacas lecheras en pastoreo. Arch. Latinoam. Prod. Anim. 15:85-97.

Galindo, J., N. González, Y. Marrero, A. Sosa, T. Ruiz, T. Febles, V.Torres, A. Aldana, G. Achang, O. Moreira, L. Sarduy, y A. Noda. 2014. Efecto del follaje de plantas tropicales en el control de la producción de metano y la población de protozoos ruminales in vitro. Rev. Cubana Cienc. Agríc. 48:359-364. 
Galindo, J., N. González, I. Scull, Y. Marrero, A. Sosa, A. Aldana, O. Moreira, D. Delgado, T. Ruiz, G. Febles, V. Torres, O. La O, L. Sarduy, A. Noda, y O. Achang. 2012. Efecto de Samanea saman (Jacq.) Merr., Albizia lebbeck (L.) Benth y Tithonia diversifolia (Hemsl.) Gray (material vegetal 23) en la población de metanógenos y en la ecología microbiana ruminal. Rev. Cubana Cienc. Agríc. 46:273-278.

Galindo, J., N. González, A. Sosa, T. Ruíz, V. Torres, A. Aldana, H. Díaz, O. Moreira, L. Sarduy, y A. Noda. 2011. Efecto de Tithonia diversifolia (Hemsl.) A. Gray (botón de oro) en la población de protozoos y metanógenos ruminales en condiciones in vitro. Rev. Cubana Cienc. Agríc. 45:33-37.

Gallego, L.A., L. Mahecha, y J. Angulo. 2014. Potencial forrajero de Tithonia diversifolia Hemsl. A Gray en la producción de vacas lecheras. Agron. Mesoam. 25:393-403.

García-González, R., S. López, M. Fernández, and J.S. González. 2008. Dose-response effects of Rheumofficinale root and Frangula alnusbark on ruminal methane production in vitro. Anim. Feed Sci. Technol. 145:319-334.

Giger-Reverdin S., D.Sauvant, J. Tessier, G. Bertin, and P. Morand-Fehr. 2004. Effect of live yeast culture supplementation on rumen fermentation in lactating dairy goats. SA J. Anim. Sci. 34:59-61.

Gualberto, R., O. Souza, N. Costa, C. Braccialli, e L. Gaion. 2010. Influência do espaçamento e do estádio de desenvolvimento da planta na produção de biomassa e valor nutricional de Tithonia diversifolia (hemsl.) Gray. Nucleus 7(2):135-149.

Harfoot, C., and G. Hazlewood.1997. Lipid metabolism in the rumen. In: P.N. Hobson, and C.S. Stewart, editors, The rumen microbial ecosystem. Chapman and Hall, London, GBR. p. 382-426.

Hashem, R., and M. Harb. 2006. The effect of adding protected fat in the ration of lactating awassi ewes and fattening lambs. Jordan J. Agr. Sci. 2:35-44.

Hiai, S., H. Oura, and T. Nagakajima. 1976. Color reaction of some sapogenins and saponins with vanillin and sulphuric acid. Planta Medica 29:116-122.

IDEAM (Instituto de Hidrología, Meteorología y Estudios Ambientales). 1999. Cartas climatológicas mensuales, Aeropuerto Olaya Herrera (Medellín). http://bart.ideam.gov.co/cliciu/mede/temperatura.htm (consultado 10 jun. 2016).

IPCC (Panel Intergubernamental sobre Cambio Climático). 2007. Climate change 2007: synthesis report. https://www.ipcc.ch/ pdf/assessment-report/ar4/syr/ar4_syr_sp.pdf (consultado 10 jun. 2016).

Jacob, A., V. Balakrishnan, and C. Kathirvelan. 2012. Effect of amount and source of vegetable oils in a high fibrous cattle diet on in vitro rumen fermentation, nutrient degradability and rumen cis-9, trans-11 CLA concentration. J. Appl. Anim. Res. 40:148-153.

Jalc, D., S. Kisidayova, and F. Nerud. 2002. Effect of plant oils and organic acids on rumen fermentation in vitro. Folia Microbiol. 47:171-177.

Janssen, P. 2010. Influence of hydrogen on rumen methane formation and fermentation balances through microbial growth kinetics and fermentation thermodynamics. Anim. Feed Sci. Technol. 160:1-22.

Kongmun, P., M. Wanapat, P. Pakdee, C. Navanukraw, and Z. Yu. 2011. Manipulation of rumen fermentation and ecology of swamp buffalo by coconut oil and garlic poder supplementation. Liv. Sci. 135:84

Kurihara, M., T. Magner, H. McCrabb, and G. McCrabb. 1999. Methane production and energy partition of cattle in the tropics. Brit. J. Nutr. 81:227-234.

La O, O., H. González, A. Orozco, Y. Castillo, O. Ruíz, A. Estrada, F. Ríos, E. Gutiérrez, H. Bernal, D. Valenciaga, B. Castro, y Y. Hernández. 2012. Composición química, degradabilidad ruminal in situ y digestibilidad in vitro de ecotipos de Tithonia diversifolia de interés para la alimentación de rumiantes. Rev. Cubana Cienc. Agríc. 46:47-56. 
Liu, S.J., D.P. Bu, J.Q. Wang, L. Liu, S. Liang, H.Y. Wei, L.Y. Zhou, D. Li, and J.J. Loor. 2012. Effect of incremental levels of fish oil supplementation on specific bacterial populations in bovine ruminal fluid. J. Anim. Physiol. Anim. Nutr. (Berl.) 96:9-16.

Liu, H., V. Vaddella, and D. Zhou. 2011. Effects of chestnut tannins and coconut oil on growth performance, methane emission, ruminal fermentation, and microbial populations in sheep. J. Dairy Sci. 94:6069-6077.

López, S., and C.J. Newbold. 2007. Analysis of methane. In: H.P.S. Makkar, and P.E. Vercoe, editors, Measuring methane production from ruminants. IAEA, FAO, Springer, Dordrecht, HOL. p. 1-10.

Machmüller, A., D. Ossowski, M. Wanner, and M. Kreuzer. 1998. Potential of various fatty feeds to reduce methane release from rumen fermentation in vitro (Rusitec). Anim. Feed Sci. Technol. 71:117-130.

Mahecha, L., J. Escobar, J. Suárez, y L. Restrepo. 2007. Tithonia diversifolia (hemsl.) Gray (botón de oro) como suplemento forrajero de vacas F1 (Holstein por Cebú). Liv. Res. Rural Dev. 19(2):16. http:// www.lrrd.org/lrrd19/2/mahe19016.htm

Mahecha, L., y M. Rosales. 2005. Valor nutricional del follaje de botón de oro Tithonia diversifolia (Hemsl.) Gray, en la producción animal en el trópico. Liv. Res. Rural Dev. 17(9):100. http://www.lrrd.org/ lrrd19/2/mahe19016.htm

Maina, I., S. Abdulrazak, C. Muleke, and T. Fujihara. 2012. Potential nutritive value of various parts of wild sunflower (Tithonia diversifolia) as source of feed for ruminants in Kenya. J. Food Agric. 10:632-635.

Makkar, H. 2003. Quantification of tannins in tree and shrub foliage. Determination of both tannin and protein. Kluwer Academic Publishers, Dundrecht, HOL. https://books.google.com.co/books?hl=es\&lr=\&id=hvulr-9ok_wC\&oi=fnd\&pg=PR1\&dq=Q uantification+of+tannins+in+tree+and+shrub+foliage.+Determination+of+both+Tannin+and+protein\&ots=FhAxrE1aVF $\&$ sig=CYD3MzgT-dDTxD-yUd8t3FJ5nAE\#v=onepage\&q=Quantification\%20of\%20tannins\%20in\%20tree $\% 20$ and $\% 20$ shrub\%20foliage.\%20Determination\%20of\%20both\%20Tannin\%20and\%20protein \&f=false (accessed 22 jun. 2016).

Marín, A. 2013. Estimación del inventario de emisiones de metano entérico de ganado lechero en el departamento de Antioquia, Colombia. Tesis MSc., Universidad Nacional de Colombia, Medellín, COL.

Marín, A., L. Giraldo, y G. Correa. 2014. Parámetros de fermentación ruminal in vitro del pasto Kikuyo (Pennisetum clandestinum). Liv. Res. Rural Dev. 26(3). http://www.lrrd.org/lrrd26/3/mari26057.html

Martin, C., D. Morgavi, and M. Doreau. 2010. Methane mitigation in ruminants: from microbe to the farm scale. Animal. 4(3):351-365.

Martínez, A., M. Pérez, L. Pérez, G. Gómez, y D. Carrión. 2011. Efecto de las fuentes de grasa sobre la digestión de la fibra en los rumiantes. REDVET 12:7. http://www.veterinaria.org/revistas/redvet/n070711/071103.pdf

Mauricio, R., R. Ribeiro, S. Silveira, P. Silva, L. Calsavara, L. Pereira, and D. Paciullo. 2014. Tithonia diversifolia for ruminant nutrition. Trop. Grassl. 2:82-84.

McDougall, E.I. 1948. Studies on ruminant saliva. 1. The composition and output of sheep's saliva. Biochem. J. 43:99-109.

Medina, M., E. García, L. González, L. Cova, y P. Morantinos. 2009. Variables morfo-estructurales y de calidad de la biomasa de Tithonia diversifolia en la etapa inicial de crecimiento. Zootec. Trop. 27:121-134.

Montgomery, S., J. Drouillard, T. Nagaraja, E. Titgemeyer, and J. Sindt. 2008. Effects of supplemental fat source on nutrient digestion and ruminal fermentation in steers. J. Anim. Sci. 86:640-650.

Moss, A.R., J.P. Jouany, and J. Newbold. 2000. Methane production by ruminants: its contribution to global warming. Ann. Zootech. 49:231-253.

Muetzel, S., E. Hoffmann, K. And Becker. 2003. Supplementation of barley straw with Sesbania pachcarpa leaves in vitro: effects on fermentation variables and rumen microbial concentration structure quantified by ribosomal RNA-targeted probes. Br. J. Nutr. 89:445-453. 
Naranjo, J., y C. Cuartas. 2011. Caracterización nutricional y de la cinética de degradación ruminal de algunos de los recursos forrajeros con potencial para la suplementación de rumiantes en el trópico alto de Colombia. Rev. CES Med. Vet. Zootecn. 6(1):9-19. http://revistas.ces.edu.co/index.php/mvz/ article/view/1489/993

Navas, A. 2008. Efecto de los sistemas silvopastoriles en la reducción del estrés calórico y su importancia en la producción bovina tropical. Rev. El Cebú 359:14-17.

Newbold, C., S. Hassan, J. Wang, M. Ortega, and R. Wallace.1997. Influence of foliage from African multipurpose trees on activity of rumen protozoa and bacteria. Br. J. Nutr. 78:237-249.

NRC (National Research Council). 2001. The nutrient requirement of dairy cattle. $7^{\text {th }}$ ed. National Academy Press, WA, USA.

Panyakaew, P., G. Goel, M. Lourenço, C. Yuangklang, and V. Fievez. 2013. Medium-chain fatty acids from coconut or krabok oil inhibit in vitro rumen methanogenesis and conversion of non-conjugated dienoic biohydrogenation intermediates. Anim. Feed Sci. Technol. 180:18-25.

Patra, A., and J. Saxena. 2010. A new perspective on the use of plant secondary metabolites to inhibit methanogenesis in the rumen. Phytochem. 71:1198-1222.

Patra, A. 2013. The effect of dietary fats on methane emissions, and its other effects on digestibility, rumen fermentation and lactation performance in cattle: A meta-analysis. Liv. Sci. 155:244-254.

Porter, L., L. Hrstich, and B. Chan. 1986. The conversion of procyanidins and prodelphinidins to cianidin and delphidin. Phytochem. 25:223-230.

Posada, S., G. Montoya, y A. Ceballos. 2005. Caracterización de los taninos en la nutrición de rumiantes. En: A. Ceballos et al., editores, Taninos en nutrición de rumiantes. Fondo Editorial Biogénesis, COL. p. 161-180. https://aprendeenlinea.udea. edu.co/revistas/index.php/biogenesis/article/view/326396/20783668 (consultado 10 jul. 2016).

Posada, S., y R. Noguera. 2005. Técnica in vitro de producción de gases: una herramienta para la evaluación de alimentos para rumiantes. Liv. Res. Rural Dev. 17(36). http://www.lrrd.org/ lrrd17/4/posa17036.htm (consultado10 may. 2016).

Posada, S., R. Noguera, y D. Bolívar. 2006. Relación entre presión y volumen para la implementación de la técnica in vitro de producción de gases. Rev. Col. Cienc. Pecu. 19:407-414.

Puerto, L.E. 2012. Evaluación química de tres especies con potencial forrajero del trópico alto y medio. UNAD, MEX. http:// repository.unad.edu.co/bitstream/10596/1074/1/Tesis.pdf (consultado 27 may. 2016)

Ramírez, J.F., S. Posada, y R. Noguera. 2014. Metanogénesis ruminal y estrategias para su mitigación. CES Med. Vet. Zootec. 9(2):307-323.

Ramírez, J., S. Posada, and R. Rosero. 2015a. Effect of lovastatin on in vitro methane production and dry matter digestibility of kikuyu grass (Cenchrus clandestinus). Rev. CES Med. Vet. Zootec. 10(2):111-121.

Ramírez, J., S. Posada, and R. Rosero. 2015b. Effects of Kikuyu grass (Pennisetum clandestinum) age and different forage: concentrate ratios on methanogenesis. Rev. MVZ. Córdoba. 20:4726-4738.

Rivera, J., J. Naranjo, C. Cuartas, y F. Arenas. 2013 Fermentación in vitro y composición química de algunos forrajes y dietas ofrecidas bajo un Sistema Silvopastoril en el trópico de altura. Liv. Res. Rural Dev. 25(10). \#174. http://www.lrrd.org/ lrrd25/10/rive25174.htm

Rodríguez, R., M. Fondevilla, and C. Castrillo. 2009. In vitro ruminal fermentation of Pennisetum purpureum CT-115 supplemented with four tropical browse legume species. Anim. Feed Sci. Technol. 151:65-74.

Rosales, M. 1996. In vitro assessment of the nutritive value of mixtures of leaves from tropical fodder trees. Dr. Thesis, Oxford University, Oxford, GBR. 
Santacoloma, L., y J. Granados. 2012. Interrelación entre el contenido de metabolitos secundarios de las especies Gliricidia sepium y Tithonia diversifolia y algunas propiedades físicoquímicas del suelo. RIAA 3(1):53-62.

SAS. 2004. User`s guide, versión 9.1.3. SAS Institute Inc., Cary, NC, USA.

Schink, B. 2006. Syntrophic associations in methanogenic degradation. In: J. Overmann, editor, Molecular basis of symbiosis. Springer, HOL. p. 1-19.

Smith, A., E. Zoetendal, and R. Mackie. 2005. Bacterial mechanisms to overcome inhibitory effects of dietary tannins. Microbial Ecol. 50:197-205.

Soliva, CR., and H. Hess. 2007. Measuring methane emission of ruminants by in vitro and in vivo techniques. In: H. Makkar, and P. Vercoe, editors, Measuring methane production from ruminants. Springer, HOL. p. 15-31.

Theodorou, M.K., B.A. Williams, M.S. Dhanoa, A.B. Mcallan, and J. France. 1994. A simple gas production method using a pressure transducer to determine the fermentation kinetics of ruminant feeds. Anim. Feed Sci. Technol. 48:185-197.

Toral, P., A. Belenguer, P. Frutos, and G. Hervás. 2009. Effect of the supplementation of a high-concentrate diet with sunflower and fish oils on ruminal fermentation in sheep. Small Rumin. Res. 81:119-125.

Vafa, T., A. Naserian, A. Moussavi, R. Valizadeh, and M. Mesgaran. 2009. Effects of different levels of fish oil and canola oil on in vitro dry matter and organic matter digestibility. Res. J. Biol. Sci. 4:1171-1174.

Van Soest., P. 1994. Nutritional ecology of the ruminant. $2^{\text {nd }}$ ed. Cornell University Press, USA.

Vargas, J., E. Cárdenas, M. Pabón, y J. Carulla. 2012. Emisión de metano entérico en rumiantes en pastoreo. Arch. Zootec. 61:51-66.

Verdecia, D., J. Ramírez, I. Leonard, Y. Álvarez, Y. Bazán, R. Bodas, S. Andrés, J. Álvarez, F. Giráldez, y S. López. 2011. Calidad de la Tithonia diversifolia en una zona del Valle del Cauto. REDVET 12(5). http:// www.veterinaria.org/revistas/ redvet/n050511/051113.pdf

Wang, Q., M. Kuninobu, H.I. Ogawa, and Y. Kato. 1999. Degradation of volatile fatty acids in highly efficient anaerobic digestion. Biomass Bioenergy 16:407-416.

Wina, E., S. Muetzel, E. Hoffmann, H. Makkar, and K. Becker. 2005. Saponins containing methanol extract of Sapindus rarak affect microbial fermentation, microbial activity and microbial community structure in vitro. Anim. Feed Sci. Technol. 121:159-174.

Wolin, M.J., and T.L. Miller. 2006. Control of rumen methanogenesis by inhibiting the growth and activity of methanogens with hydroxymethylglutaryl-SCoA inhibitors. Intr. Congress Series 1293:131-137.

Zhang, C., Y. Guo, Z. Yuan, Y. Wu, J. Wang, J. Liu, and W. Zhu. 2008. Effect of octadeca carbon fatty acids on microbial fermentation, methanogenesis and microbial flora in vitro. Anim. Feed Sci. Technol. 146:259-269.

Zhou, Y., H. Maoa, F. Jianga, J. Wanga, J. Liua, and C. McSweeney. 2011. Inhibition of rumen methanogenesis by tea saponins with reference to fermentation pattern and microbial communities in Hu sheep. Anim. Feed Sci. Technol. 166-167:93-100. 